\title{
1. Gattungskonstitution: Charles Baudelaires Petits poèmes en prose
}

Die Konstitution des neuen Gattungsmodells poème en prose durch Charles Baudelaire (1821-1867) erfolgte als direkte Reaktion auf den nach außen hin zwar stabil wirkenden, im Grunde aber höchst krisenanfälligen, weil anachronistischen Zustand des französischen Literatursystems um die Mitte des 19. Jahrhunderts. Dieses wirkte vor allem deshalb - verglichen mit der Entwicklung in den meisten europäischen Nachbarländern - hoffnungslos zurückgeblieben, weil es auch nach dem Aufkommen narrativer Prosagenres strikt an der herkömmlichen Superiorität der Versdichtung festgehalten, ${ }^{1}$ zugleich aber jede Erweiterung des lyrischen Gestaltungsspielraums unterbunden hatte. ${ }^{2}$ Das überaus schmale Spektrum anerkannter poetischer Formen, das sich im Grunde seit dem 18. Jahrhunderts nicht nennenswert verändert hatte, zwang die Autoren dazu, sich immer und immer wieder der gleichen literarischen Ausdrucksmittel zu bedienen. Wenn man bedenkt, daß in Frankreich allein zwischen 1840 und 1850 rund 1800 Personen als Verfasser versifizierter Texte hervorgetreten sind (wobei die Anzahl der von ihnen publizierten Werke natürlich noch weit höher angesetzt werden muß), ${ }^{3}$ dann wird erahnbar, welch hohen Grad an

1 „Dans la France littéraire du XIXe siècle, le vers et le prose représentent bien plus que des sformes ou des ttechniquess neutres « $»$ Quiconque pratique la prose sait en effet qu'il se situe dans les zones subaltemes de la littérature; quiconque pratique le vers (dans les poésies comme au théâtre) sait qu'il s'insère dans la véritable littérature." José Lambert: Vers et prose à l'époque romantique, ou la hiérarchie des genres dans les lettres françaises. In: Du romantisme au surnaturalisme. Hommage à Claude Pichois. Éd. par James S. Patty. Neuchâtel: $\grave{A}$ la Baconnière 1985, S. 41.

Nichts illustriert den fundamentalen Unterschied der beiden Literatursysteme links und rechts des Rheins besser als der Umstand, daß in Frankreich die ,Erfindunge des Prosagedichts der Entwicklung des vers librer vorausgeht, während es sich in Deutschland genau anders herum verhält. Zudem liegen zwischen beiden Innovationen im deutschsprachigen Raum ganze 130 Jahre, im Nachbarland aber nicht einmal drei Dezennien.

3 Diese Angabe benuht auf den Forschungen von Robb, der die mexplosion démographique des versificateurs im Frankreich der Jahrhundertmitte erstmals eingehend untersucht hat; Graham Robb: La poésie de Baudelaire et la poésie française 1838-1852. O.O.: Aubier 1993 (= Collection Critiques), S. 12. Daß damit noch nicht die tatsächliche Menge aller Publikationen in gebundener Sprache erfaßt ist, hängt zum einen damit zusammen, daß die "Bibliographie de la France n'enregistre pas tous les volumes publiés en province, à l'étranger 
Automatisierung die literarische Produktion zu dieser Zeit faktisch erreicht hat. Bei einer nüchternen Bestandsaufnahme zeigt sich denn auch: "La prosodie française était devenue une machine frable, [...] un mécanisme à l'aide duquel on pouvait fabriquer des poèmes nombreux et plus ou moins lisibles» ${ }^{4}$. Die massenhafte Reproduktion bestehender Vertextungsweisen, die für die wuniformité apparente de la poésie française " ${ }^{5}$ sorgte, ließ aber zugleich auch das Innovationsbedürfnis im Bereich der Lyrik immer drängender werden. Da dieses jedoch innerhalb der Parameter des bestehenden Systems nicht mehr aufgefangen werden konnte, war über kurz oder lang eine grundlegende Veränderung des Gattungsensembles unumgänglich. Baudelaire nun darf als derjenige Autor gelten, der mit seinen Texten eine solche zunächst inhaltlich, dann aber auch formal in der gebotenen Radikalität bewirkt hat - eine Leistung, die ihm in der Forschung zu Recht den Titel eines Ahnherrn der literarischen Moderne eintrug. ${ }^{6}$

Der Durchbruch zu neuen Gattungsstrukturen vollzog sich bei ihm im Rahmen einer ästhetischen Theorie der smodernité, welche die Dogmen des ästhetischen Klassizismus rigoros verabschiedete und den Annahmen der idealistischen Kunsttheorie ein folgenreiches Alternativmodell entgegenstellte. Da Baudelaires Ziel darauf gerichtet war, "[d']établir une théorie rationelle et historique de beau, en opposition avec la théorie du beau unique et absolu« (Oc II, S. 685), temporalisierte er die Zentralkategorie bisheriger Ästhetik - " La beauté absolue et éternelle n'existe pas« (Oc II, S. 493) konstatiert er apodiktisch im Salon de $1846^{7}$ - und definierte sie gleichzeitig inhaltlich völlig neu, indem er das, was bisher traditionellerweise zum Nichtschönen gerechnet und damit aus dem Bereich der Kunstlehre ausgegrenzt wurde, programmatisch in die Definition des Schönen hereinnahm. So erklärt er in seiner wichtigsten theoretischen "Programmschrift" ${ }^{8}$ Le Peintre de la vie moderne (1863): "Le beau est fait d'un élément éternel, invariable, dont la quantité est excessivement difficile à déterminer, et d'un élément relatif, circonstanciel, qui sera, si l'on veut, tour à

ou à compte d'auteur", und zum anderen damit, daß "plusieurs poètes gardent l'anonymat, ou ne publient leurs vers que dans les volumes collectifs, ou dans des journauxi; ebd., S. 11.

Ebd.

5 Ebd., S. 10.

6 Bei Schödlbauer etwa heißt es in gewollt pointierender Zuspitzung: „Die modeme Lyrik ist eine Erfindung Baudelaires.« Ulrich Schödlbauer. Die Modernitätsfalle der Lyrik. In: Merkur 49 (1995), Nr. 551, S. 171.

7 Mit der mradikalen Verzeitlichung des Schönen» begründet Baudelaire im Grunde die Ästhetik der Modeme; Eckhardt Köhn: Straßenrausch. Flanerie und kleine Form. Versuch zur Literaturgeschichte des Flaneurs bis 1933. Berlin: Das Arsenal 1989, S. 63. Vgl. hierzu Carsten Zelle: Die doppelte Ästhetik der Moderne. Revisionen des Schönen von Boileau bis Nietzsche. Stuttgart/Weimar: Metzler 1995.

8 Werner Ross: Baudelaire und die Modeme. Porträt einer Wendezeit. München/Zürich: Piper 1993 (= Serie Piper 1855), S. 178. 
tour ou tout ensemble, l'époque, la mode, la morale, la passion." (Oc II, S. 685) ${ }^{9}$ Das Verhältnis beider wird freilich nicht als eines von Substanz und Akzidens gedacht; vielmehr erscheint die Annahme des wéternek eher als eine Art transzendentaler Ermöglichungsgrund für das Erscheinen des Flüchtigen und Wechselhaften, ${ }^{10}$ das sich schließlich als Synonym der Moderne schlechthin erweist: "La modernité, c'est le transitoire, le fugitif, le contingent, la moitié de l'art, dont l'autre moitié est l'éternel et l'immuable.« (Oc II, S. 695) Die Aufgabe des modernen Künstlers bestehe deshalb darin, sde tirer l'éternel du transitoire« (Oc II, S. 694). ${ }^{11}$

Baudelaire ging es also nicht einfach darum, die Eigenwertigkeit zeitgenössischen Schreibens in Abgrenzung zu den anerkannten historischen Mustern zu legitimieren, sondern er war vielmehr bestrebt, die Bedingungen von Kunst unter den radikal veränderten Umständen einer Gegenwart zu klären, deren wichtigstes Merkmal - eine ungekannte Dynamik temporaler Akzeleration - zu einem folgenschweren Bruch mit aller bisherigen Tradition führt. Mit seiner endgültige Absage an das Ideal transhistorischer Schönheit erklärte er das Ephemere und Arbiträre zum eigentlichen ästhetischen Ausdrucksmedium, auch wenn oder besser: gerade weil es nicht den Forderungen des klassischen Schönheitsbegriffs entspricht, sondern wsouvent bizarre, violent, excessif« (Oc II, S. 724) sei. ${ }^{12}$ Im Bereich der Literatur spiegelt sich das Ver-

9 Mit der Unterscheidung zwischen einem »beau rélatifu und einem »beau éternelı nimmt Baudelaire ein begriffliches Gegensatzpaar auf, das im Rahmen der 'Querelle des anciens et des modemes von den Brüdem Charles und Claude Perrault geprägt worden ist, vgl. hierzu das Kapitel "Ein rdoppeltes $\mathrm{Maß}$ des Schönen - beau absolu und beau relatif in Perraults Paralfele bei Carsten Zelle: Die doppelte Ästhetik der Modeme. Revisionen des Schönen von Boileau bis Nietzsche, S. 87-97. Wie Jauß gezeigt hat, grenzt sich Baudelaire freilich von der bis dato eingeführten Terminologie, welche die Bezeichnungen mancien" und "moderner durchweg adjektivisch gebraucht, bewußt ab, und erhebt den SubstantivNeologismus »la modernité szum Programmwort einer neuen Ästhetik; Hans Robert Jauß: [Stichwort] Antiqui/modemi (Querelle des Anciens et des Modernes). In Historisches Wörterbuch der Philosophie. Unter Mitwirkung von mehr als 700 Fachgelehrten [...] hrsg. von Joachim Ritter. Bd. 1. Darmstadt: Wissenschaftliche Buchgesellschaft 1971, Sp. 414. Der geregelten Sukzession von santiquir und moderni, wie sie für die ’Quereller kennzeichnend ist, war damit auch begrifflich ein Ende gesetzt.

10 Zugleich widerspricht Baudelaire aber auch einer platonisierenden Festschreibung des wéternek. Indem er es als mimpossibilité «, ja als mabsurdité» charakterisiert - "l'idéal absolu est une bêtise" (Oc II, S. 455) ist im Salon de 1846 zu lesen -, konstruiert er das Ideal als negative Denkfigur. Dieser gewissermaßen inverse Platonismus in Baudelaires Ästhetik wäre noch genauer zu untersuchen. Einzelne platonische Komponenten seiner Kunstphilosophie hat immerhin Eigeldinger bereits systematisch herausgearbeitet, vgl. Marc Eigeldinger: Le platonisme de Baudelaire. Neuchâtel: Édition de la Baconnière 1951.

11 Wenn es im Entwurf zu einer Vorrede der Flewrs du mal heißt, Ziel der Gedichte sei gewesen, sd'extraire la beauté du Malк (Oc I, S. 181), dann zeigt sich noch einmal deutlich, daß "mal« von Baudelaire als Teilbereich des »transitoire" verstanden wird.

12 Die Poetik Baudelaires ist ein anschauliches Beispiel dafür, wie der Verzeitlichungsdruck, dem die Ordnung des Wissens seit dem Ende des 18. Jahrhunderts permanent ausgesetzt 
hältnis von séternel« und stransitoire« nach Baudelaire in der konflikthaften Spannung zwischen sPoesier und Prosa. Die Versdichtung ziele mit ihren formalen Regularien wie Strophik, Metrik und Reimzwang, aber auch mit ihrem elaborierten Sprachcode, der nur ein bestimmtes, ausgesuchtes Vokabular zuläßt, ${ }^{13}$ eben darauf ab, einem Ideal Gestalt zu geben: wle principe de la poésie est, strictement et simplement, l'aspiration humaine vers une Beauté supérieure, et la manifestation de ce principe est dans un enthousiasme, un enlévement de l'1âme« (Oc II, S. 114). ${ }^{14}$ Durch ihre Fixierung auf eine transhistorische Größe befinde sich die Versdichtung aber in ständiger Gefahr, »de perdre beaucoup du côté de la réalité« (Oc II, S. 121). Da ihre sprachlich-formalen Mittel zudem auf die Errichtung einer harmonischen Textordnung gerichtet seien und die Aufgabe hätten, sd'éviter la précipitation et la saccade« (Oc II, S. 671), müsse die `Poesier sich gegenüber den Erscheinungen der modernen Welt abschließen: "La poésie lyrique s'élance, mais toujours d'un mouvement élastique et ondulé. Tout ce qui est brusque et cassé lui déplaît, et elle le renvoie au drame ou au roman de maurs. « (Oc II, S. 126) Mit der Feststellung: nla poésie lyrique ennoblit tout" (Oc II, S. 671) umreißt Baudelaire schließlich zusammenfassend Leistung und Problematik der Versdichtung.

Um der Tendenz zur Erhebung und Veredlung zu entgehen und dennoch den Forderungen der Modernität zu genügen, versuchte Baudelaire zunächst, die Grenzen des lyrisch Darstellbaren so weit wie nur möglich zu erweitern. Konsequenter Ausdruck dieser Poetik ist die Gedichtsammlung Les Fleurs $d u$ mal $(1857),{ }^{15}$ die ihrem Autor prompt ein Gerichtsverfahren wegen Mißachtung der Religion und Verlet-

war, dem sich aber die Ästhetik in Frankreich hartnäckig widersetzte, mit einem Mal in aller Wucht auf das literarische System durchschlägt. Während etwa der Roman sich als Textsorte präsentierte, die auf den Temporalisierungsimperativ in vielfältiger Weise reagiert, definierte sich die Versdichtung geradezu trotzig als autonomer Bereich überzeitlicher ästhetischer Werte. Die quasimythologischen Begründungsformeln, die diesen Anspruch legitimieren sollen, sind dabei äußerst vielfältig. Zu ihnen gehört etwa die im 18. Jahrhundert von Blackwell, Lowth und Condillac formulierte, von Hamann und Herder dann in Deutschland eingeführte Annahme eines ahistorischen, paradiesischen Ursprungs der Poesie, welche den weiteren Fortgang der literarischen Entwicklung zwangsläufig als Prozeß der Depravierung erscheinen ließ. sPoesier wird auf diese Weise zu einem säkularisierten Religionsersatz, der zur gezielten Projektion von Heilserwartungen dient.

13 Wie Baudelaire im Aufsatz über Thénphile Gautier schreibt, konstituieren für ihn ein Gedicht mnon pas le mètre et la rime, mais la pompe ou l'énergie concise de son langageu (Oc II, S. 121).

14 Das damit einhergehende wirkungsästhetische Element gebundener Rede wird von Baudelaire besonders in den Notes noutelles sur Edgar Poe (1857) hervorgehoben; dort heißt es: mun poème ne mérite son titre qu'autant qu'il excite, qu'il enlève l'âme, et la valeur positive d'un poème est en raison de cette excitation, de cet enlèvement de l'âmeu (Oc II, S. 332).

15 Schon der Titel weist jene Gegensatzstruktur auf, die für alle poetischen Werke Baudelaires charakteristisch ist: mun oxymoron [...] de la Beauté et du Malk; Claude Pichois/Jean Ziegler: Baudelaire. Paris: Julliard 1987 ( $=$ Collection »Les Vivantsı), S. 337. 
zung der guten Sitten bescherte. ${ }^{16}$ Die Wahl des semantisch polyvalenten $>$ Bösen ${ }^{17}$ als Leitbegriff (und nicht etwa der auf den Bereich des Ästhetischen beschränkten Kategorie des Häßlichen ${ }^{18}$ ) war dabei Ausdruck des Versuchs, Religion, Ethik und Ästhetik simultan zu attackieren, ${ }^{19}$ um so der Literatur neue Freiheiten zu erobern. Die in den Fleurs du mal versammelten Texte thematisieren gezielt jene tabuisierten Bereiche der Wirklichkeit, die gemeinhin einer poetischen Gestaltung für unwürdig erachtet wurden und für die in vielen Fällen auch außerhalb der Lyrik kein akzeptiertes sprachliches Register vorhanden war. So schildert Baudelaire im Rahmen seiner Verslyrik nicht nur einen fliegenbedeckten, von Maden zerfressenen, verwesenden Tierleib (Une charogne), er scheut sich auch nicht, die seit der Antike topische poetische Inspirationsinstanz der Muse als Prostituierte (La Muse vénale) und Gott als blutrünstigen Sadisten (Le Reniement de Saint Pierre) darzustellen. Die Anrufung Satans als religiöser Bezugsinstanz des Bösen, die Verletzung moralischer Tabus durch die unverhüllte Darstellung von Kriminalität und Sexualität und die Kultivierung einer ¿Ästhetik des Häßlichenc illustrieren einzelne Facetten der von ihm angestrebten radikalen Umkehrung des überkommenen Wertespektrums.

16 Vgi. hierzu Klaus Heitmann: Kunst und Moral. Zur Problematik des Prozesses gegen die Fleurs du Mal. In: Deutsche Vierteljahrsschrift für Literaturwissenschaft und Geistesgeschichte 34 (1960), S. 46-65, sowie K. H.: Der Immoralismus-Prozeß gegen die französische Literatur im 19. Jahrhundert. Bad Homburg v.d.H./Berlin/Zürich: Gehlen 1970 (= Ars poetica 9 ).

17 Zur Kategorie des Bösen bei Baudelaire siehe Marcel A. Ruff: L'Esprit du mal et l'esthétique baudelairienne. Paris: Colin 1955 (= Études littéraires); Reprint: Geneva: Slatkine 1972, und Arnolds Grava: L'Aspect métaphysique du mal dans l'æuvre littéraire de Charles Baudelaire et d'Edgar Allan Poe. Lincoln: University of Nebraska 1956 (= University of Nebraska studies N.S. 15); Reprint: Geneva: Slatkine 1976. Vgl. allgemein auch Karl S. Guthke: Der Mythos des Bösen in der europäischen Romantik. In: Colloquia Germanica 2 (1968), S. 1-36, und Anke Wiegand: Die Schönheit und das Böse. München: Pustet 1967 (= Epimeleia 7 ).

18 Eine derartige Ästbetik des Häßlichen (1853) wurde von Karl Rosenkranz unter Anknüpfung an die hegelsche Philosophie ungefähr zeitgleich in Deutschland entwickelt. Zur Rolle des Häßlichen in der Geschichte der Ästhetik vgl. Günther Oesterle: Entwurf einer Monographie des ästhetisch Häßlichen. Zur Geschichte einer ästhetischen Kategorie von Friedrich Schlegels Studium-Aufsatz bis zu Karl Rosenkranz' Ästbetik des Häßlichen als Suche nach dem Ursprung der Moderne. In: Zur Modemität der Romantik. Hrsg. von Dieter Bänsch. Stuttgart: Metzler 1977 (= Literaturwissenschaft und Sozialwissenschaften 8), S. 217-304, sowie Holger Funk: Ästhetik des Häßlichen. Beiträge zum Verständnis negativer Ausdrucksformen im 19. Jahrhundert. Mit einem Geleitwort von Horst Denkler. Berlin: Agora Verlag 1983 (= Canon 9).

19 Nach Rosenkranz ist „das Böse das radicale, das absolute, das ethische und religiöse Häßliche«; Karl Rosenkranz: Ästhetik des Häßlichen. [Reprint der Ausgabe Königsberg 1853.] Mit einem Vorwort zum Neudruck von Wolfhart Henckmann. Darmstadt: Wissenschaftliche Buchgesellschaft 1989, S. 325. 
Die schockierende Wirkung der Versgedichte resultiert freilich zu einem nicht geringen Teil aus der krassen Diskrepanz zwischen smodernem Inhalt und traditioneller Form. ${ }^{20} \mathrm{Um}$ durch den harten Form/Inhalt-Kontrast maximalen Effekt erzielen zu können, war der Autor gerade gezwungen, die - in Frankreich besonders rigiden - geltenden Normen der Prosodie strikt einzuhalten. Man hat deshalb im Hinblick auf die Fleurs du mal nicht zu Unrecht vom wclassicisme formel de Baudelaire ${ }^{21}$ gesprochen. Und obgleich sich in seiner Verslyrik seit den fünfziger Jahren kleinere Abweichungen in der metrischen Gestaltung und gelegentliche Verstöße gegen das klassische Formenrepertoire feststellen lassen, ${ }^{22}$ weisen doch erst die nach Erscheinen der Erstausgabe verfaßten Gedichte, die dann in die erweiterte Auflage von 1861 aufgenommen wurden, nennenswerte Irregularitäten auf. ${ }^{23}$ Aber auch jetzt noch gebrauchte Baudelaire "pour cent quinze des cent trente poèmes des Fleurs du $\mathrm{Mal}$ de 1861 [...] une des quatre formes suivantes: le sonnet, les alexandrins à rimes plates ou en quatrains, et les quatrains octosyllabiques ${ }^{24}$. Formale Kühnheiten, die diese Bezeichnung verdienen, unterblieben auch hier. ${ }^{25}$

Als Baudelaire erkannte, daß er innerhalb des Ausdrucksmodells der Versdichtung zwar die Spannung zwischen Form und Inhalt zu ihrem Höhepunkt treiben konnte, zusätzliche eingreifende Veränderungen des bestehenden metrisch-strophi-

20 Der Titel eines Abschnitts der Gedichtsammlung - »spleen et idéalu - benennt dieses Gegensatzverhältnis treffend.

Graham Robb: La poésie de Baudelaire et la poésie française 1838-1852, S. 214.

Robb bemerkt in diesem zusammenhang zu Recht: »la plupart des licencesı ou raudaces de sa poésie en vers sont trés subtiles, on pourrait même dire subreptices«; ebd., S. 215.

Die hauptsächliche Neuerung, ein durch Nichteinhaltung der msyntax/metre parallel und vermehrtes Enjambement gelockerter Versbau, betrifft im wesentlichen die Gedichte jenes Abschnitts, der als einziger neu in die Ausgabe von 1861 eingefügt worden ist, die $" \mathrm{Ta}$ bleaux parisiens" nämlich. Graham Chesters: Baudelaire and the Poetics of Craft. Cambridge/New York/New Rochelle/Melboume/Sydney: Cambridge University Press 1988, S. 155. Ob diese moderaten Regelverstöße aber bereits auf »a type of verse which questions its classical symmetry, and leans, however slightly, towards the rhythms, the unpredictability and the irregularity of proser hindeuten, erscheint dagegen recht fraglich; ebd., S. 156. Dennoch deutet auch Robb die gezielt eingesetzten wincongruités stylistiques " bereits als erste Ansätze zur Ausbildung eines "registre prosaïque» in der Sprachform der Fleurs du Mat, Graham Robb: La poésie de Baudelaire et la poésie française 1838-1852, S. 333 und 332. Zum Zusammenhang der lyrischen "Tableaux parisiens" mit der Prosagattung Tableau vgl. Karlheinz Stierle: Baudelaires Tableaux Parisiens und die Tradition des "Tableau de Parisu. In: Poetica 6 (1974), S. 285-322.

Graham Robb: La poésie de Baudelaire et la poésie française 1838-1852, S. 213.

25

Wie sehr Baudelaire gleichwohl überzeugt war, mit den "Tableaux parisiens» abermals in bislang ungekannte Ausdrucksfelder vorgedrungen zu sein, belegt eine briefliche Äußerung So schreibt er Anfang Juni 1859, als er dem Herausgeber der Retze franfaise, Jean Morel, das später Les Sept Vieillards betitelte Gedicht zur Publikation übersendet: "C'est le premier numéro d'une nouvelle série que je veut tenter, et je crains bien d'avoir simplement réussi à dépasser les limites assignées à la Poésie« (C I, S. 583). 
schen Gestaltungsrepertoires aber letztlich nur die Wirkung seiner Gedichte mindern würden, begab er sich auf die Suche nach einem ästhetischen Verfahren, das ihm auch ein Umstoßen der eigentlich lyrischen Strukturprinzipien möglich machen würde. Dafür bot sich in geradezu idealer Weise die Prosa an, die ja traditionell als Widerpart des >Poetischen definiert war. ${ }^{26}$ Indem Baudelaire nun den verbrauchten Mustern der Lyrik etwas grundlegend Neues im konkurrierenden Modus der Prosa entgegenzusetzen begann, ${ }^{27}$ brach er aus dem antiquierten französischen Gattungssystem aus und initiierte »un commencement absolu ${ }^{28}$. Um zu funktionieren, mußte die neue Textform freilich antithetisch an die Versdichtung gekoppelt bleiben. ${ }^{29}$ Deshalb gilt, was Frey über die Petits poèmes en prose bemerkt: "Die Prosa von Baude-

26 Wie Aufzeichnungen zum Essay L'Art philosophique belegen, war sich Baudelaire der Tatsache überaus bewußt, sdans un siècle de prose« (Oc II, S. 607) zu leben - eine Überzeugung, die ihn im übrigen mit Hegel verbindet. Zu den Gemeinsamkeiten in der Ästhetik Hegels und Baudelaires vgl. den - insgesamt allerdings unbefriedigenden - Aufsatz von Anna BrzyskiLong: Retracing Modernist Origins: Conceptual Parallels in the Aesthetic Thought of Charles Baudelaire and G.W.F. Hegel. In: Art Criticism 12 (1997), Heft 1, S. 95-111.

27 Chesters sieht dabei die Entwicklung in der Lyrik und in der Prosa parallel verlaufen. In der Lyrik könne der verstärkte Einsatz von Enjambement mas the idea of dépassementı carried into the realm of verse-technique» verstanden werden, zur selben Zeit durchbrächen die Prosagedichte dann das Regelwerk der Versdichtung völlig; Graham Chesters: Baudelaire and the Poetics of Craft, S. 146. Allerdings ebnet die so hergestellte Analogie »between aesthetic dépassementr (of the limits of poetry) and technical dépassement (of the limits of Alexandrine) « (ebd.) das Ergebnis dieser Überschreitungsakte weitgehend ein.

28 Georges Blin: Introduction aux Petits poèmes en prose. In: G. B.: Le Sadisme de Baudelaire. Paris: Librairie José Corti 1948, S. 143. Schon Klemperer sah die Konzeption des Prosagedichts als einen Akt der »Rebellion« gegen die Zwänge der normativen französischen Metrik und Strophik an; Victor Klemperer: Moderne französische Lyrik (Dekadenz - Symbolismus - Neuromantik), S. 4.

29 Die Petits poèmes en prose stellen deshalb noch wesentlich stärker als die Fleurs du mal einen konstruktiven Akt dar. Zwar destruiert Baudelaire mit dieser Textform sowohl Sprache als auch Form der Versdichtung, doch setzt er dem verbrauchten Ausdrucksmodell eben auch etwas grundlegend Neues entgegen: "Tatsächlich begnügt sich Baudelaire, wie Barbara Johnson [...] aufzeigt, beim Übergang vom Versgedicht zum Prosagedicht nicht damit, ersteres zu de-figurieren, das heißt, die Bilder oder vielmehr das implizite System der Bildlichkeit zu beseitigen: Er ersetzt es durch ein anderes; Defiguration + Refiguration, diese zweifache Arbeit verdient die Bezeichnung Transfiguration oder figurative Transposition." Gérard Genette: Palimpseste. Die Literatur auf zweiter Stufe, S. 304. Selbst wenn man die durchweg ironische Haltung der Widmung an Arsène Houssaye bedenkt, läßt sich die damit verbundene Emphase doch noch sehr deutlich in diesem Text erkennen.] Baudelaires

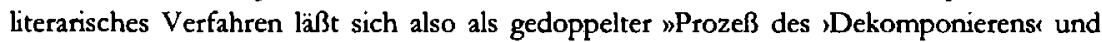
Rekomponierens « beschreiben; Erich Köhler: Vorlesungen zur Geschichte der Französischen Literatur. [Bd. 11:] Das 19. Jahrhundert III. Hrsg. von Henning Krauß und Dietmar Rieger. Stuttgart/Berlin/Köln/Mainz: Kohlhammer 1987, S. 46. Von ihm gilt exakt, was der Autor über die Imagination sagt: welle décompose toute la création, et [...] elle crée un monde nouveau, elle produit la sensation du neuf“ (Oc II, S. 621). 
laires Prosagedicht ist als Negation des Verses noch auf diesen bezogen und die rhythmische Ordnung als zerfallende erhalten. ( $^{30}$

Besonders deutlich zeigt sich dies in der experimentellen Erprobungsphase des neuartigen Gattungskonzepts: mavant même d'écrire des poèmes en prose proprement dits, Baudelaire s'est essayé à des transpositions de genre, récrivant en prose des poèmes d'abord composés en versu" ${ }^{31}$. Das allererste Beispiel einer solchen stransposition" stellen die Prosaparaphrasen zweier Versgedichte dar, die in den 1851 veröffentlichten Essay $D u$ vin et du haschisch integriert wurden. ${ }^{32}$ Allerdings läßt sich zu diesem Zeitpunkt noch kein klarer Verwendungszweck der Texte erkennen. ${ }^{33}$ Erst Mitte der fünfziger Jahre ging Baudelaire einigermaßen gezielt daran, Prosavarianten von Versgedichten herzustellen, um sich über die Funktion von sPoesier und Prosa klarzuwerden. In diesen Texten erscheint die Prosaform deutlich als Modus der Umschrift, wobei das, was zuvor in gebundener Rede ausgedrückt wurde, in ungebundene Rede transformiert ist. Eindrucksvoll belegen läßt sich diese Kontrastierung der Ausdrucksregister durch den gekoppelten Abdruck inhaltlich aufeinander bezogener Vers- und Prosagedichte in der Festschrift Hommage à C.F. Denecourt. Fontainebleau. Paysages, légendes, souvenirs, fantaisies $(1855){ }^{34} \mathrm{Da}$ sich für den

30 Hans-Jost Frey: Verszerfall. In: H.-J. F./Otto Lorenz, Kritik des freien Verses. Welche Kriterien gibt es heute für den freien Vers? Antworten auf die Preisfrage der Deutschen Akademie für Sprache und Dichtung vom Jahr 1979.] Mit einer Nachbemerkung von Horst Rüdiger. Heidelberg: Lambert Schneider 1980, S. 58. Dies zeigt sich nicht zuletzt an der Bezeichnung des neuen Genres, das Baudelaire bewußt spoime en proser nennt.

31 Charles Baudelaire: Petits poëmes [sic] en prose. Édition critique par Robert Kopp. Paris: Librairie José Corti 1969, S. XXXVIII.

32 Vgl. Oc I, S. 380f. Der Gedanke an die Übertragung von Versen in Prosa begegnet sogar schon in La Fanfarlo (1847), wo es an einer Stelle heißt: "Samuel Cramer [...] commença à mettre en prose et à déclamer quelques mauvaises stances composées dans sa première manière" (Oc I, S. 560).

33 Die Umschrift von Le Vin du chiffoniers erscheint typographisch unmarkiert und entfernt sich darüber hinaus sehr weit vom Wortlaut des Originals. Und auch bei der Prosavariante von $L ' A m e$ du $\operatorname{tin}$ läßt sich, obgleich sie durch Anführungszeichen hervorgehoben ist, der Bezug auf das Versgedicht kaum erkennen; im Grunde verleiten die Anführungsstriche eher zu der irrigen Annahme, es handle sich um ein wörtliches Zitat. In beiden Fällen wird der intertextuelle Bezug zwischen Vers- und Prosatext auch nicht annähernd ausgereizt, so daß von einem bewußten Transpositionsakt kaum gesprochen werden kann.

34 Detaillierte Informationen zur Entstehungsgeschichte der Festschrift, zu den Mitarbeitem des Bandes und der Struktur der Beiträge finden sich bei F.W. Leakey: A Festschrift of 1855: Baudelaire and the Hommage à C.F. Denecourt. In: Studies in French Literature presented to Harold W. Lawton, ed. by J.C. Ireson, I.D. Mc Farlane and Gamet Rees. Manchester: Manchester University Press 1968, S. 175-202. Die mdouble uniqueness der in der Hommage à C.F. Denecourt veröffentlichten Texte Baudelaires zeigt sich nicht nur in der gezielten Kombination von Vers- und Prosagedichten, sondem auch in deren thematischer Ausrichtung; Graham Chesters: Baudelaire and the poetics of craft, S. 157. Die Festschrift sollte nämlich, da der zu Ehrende sich besonders der forstwirtschaftlichen Kultivierung des 
Leser aber nur die Texte in sgebundener Sprache gattungsästhetisch zuordnen lieBen, mußte der Status der Prosastücke hochgradig zweifelhaft bleiben. Im Rahmen der nach wie vor gülrigen Normen des französischen Literatursystems konnten sie allenfalls als Vorstufen zu noch auszuführenden Versgebilden oder als - reichlich funktionslos wirkende - Paraphrasen lyrischer Gedichte erscheinen. Baudelaire verzichtete denn auch ab diesem Zeitpunkt auf jede weitere direkte publikatorische Verknüpfung von sPoesier und Prosa ${ }^{35}$ und präsentierte seine kurzen Prosatexte fortan ausschließlich in selbständigen Veröffentlichungen - "pour éviter d'avoir l'air de montrer le plan d'une chose à mettre en vers« (C II, S. 207). ${ }^{36}$

Waldes von Fontainebleau widmete, Gedichte über die Natur enthalten: „sur les bois, les grands chênes, la verdure, les insectes, - sur le soleil sans douter (C I, S. 248). Baudelaire freilich sah sich außerstande, dieser inhaltlichen Vorgabe zu entsprechen, und schickte statt der gewünschten »vers sur la Natureu (C I, S. 248) kurzerhand Vers- und Prosatexte über die Großstadt. Da der Brief, in dem er seine Ablehnung der Natur und seine Hochschätzung der künstlichen Lebenssphäre der Stadt begnïndet, neben den Gedichten mitabgedruckt wurde, konnte sich Baudelaire hier erstmals programmatisch als Dichter urbanen Lebens profilieren. Die Tatsache, daß die Erstveröffentlichung von Prosagedichten im Kontext der Thernatisierung von Großstadterfahrung steht, indiziert bereits, wie sehr die Entwicklung der Gattung im Zeichen der Erfassung modemer Lebenswirklichkeit erfolgt, die sich in den urbanen Zentren beispielhaft verdichtet. Dieses Interesse wird schließlich so stark, daß Baudelaire in die zweite Ausgabe seiner Fleurs du mal (1861) eine Abteilung mit dem Titel "Tableaux parisiens» einfügt. Die Stadt erscheint nun auch in der Lyrik als jener Ort, an dem das transitorische Element der Moderne am unverstelltesten greifbar wird. So heißt es etwa im Gedicht Le Cygne: wLe vieux Paris n'est plus (la forme d'une ville / Change plus vite, hélas! que le cœur d'un mortel)« (Oc I, S. 85). Dennoch dominiert die Großstadterfahnung die Lyrik nicht. Bevorzugtes Ausdrucksmedium der mfréquentation des villes énormes" und des wcroisement de leurs innombrables rapports" (Oc I, S. 276), die Baudelaire an seinen Prosagedichten hervorhebt, bleibt für ihn die ungebundener Sprache.

35 Allerdings versuchte er seine Prosagedichte auf eine Weise zu publizieren, daß sich durch die Umstände ihres Erscheinens ein Bezug zu den Gedichten der Fleurs du mal ergab. So war im Herbst 1857 als Veröffentlichungsort der Petits poèmes en prose zunächst die Zeitung Revue des Deux: Mondes geplant, wo gut zwei Jahre zuvor achtzehn Gedichte aus den Fleurs du mal abgedruckt worden waren. Eine derartige Publikation - zu der es jedoch im Endeffekt nicht kam - hätte den komplementären Charakter der zwei Werke klar hervorgehoben, den Baudelaire auch später mehrfach betonte.

Genau dies aber hat die Forschung lange Zeit angenommen. So argumentiert etwa Rauhut: "Da Baudelaire mit äußerster Langsamkeit und Sorgfalt arbeitete [...], formulierte er viele seiner Themen in Prosa, bevor er ihnen metrische Gestalt gab; in vielen Fällen hat er es aus irgendeinem Grund bei der Prosafassung bewenden lassen.« Franz Rauhut: Das französische Prosagedicht, S. 37. Neben Baudelaires Arbeitsweise wurde gelegentlich auch das Nachlassen der Schaffenskraft infolge seiner Krankheit als Grund dafür angeführt, daß die Prosatexte nicht (mehr) zu Versgedichten umgeformt worden seien; vgl. Jacques-Henry Bornecque: Les poèmes en prose de Baudelaire. In: L'Information littéraire 5 (1953), S. $177-182$. 
Hieran wird sichtbar, wie überaus schwierig es faktisch war, ein bis dato nicht existierendes Gattungsmodell als Innovation im Bewußtsein der Literaturrezipienten zu verankern. Dazu genügte nicht einfach die Publikation von Texten, vielmehr mußte der Verständnisrahmen für diese Texte mitgeliefert werden. Baudelaire stellte deshalb bei der nächsten Veröffentlichung seiner Prosagedichte ${ }^{37}$ dem Abdruck der Texte eine programmatische Vorrede in Gestalt einer - an den Chefredakteur der Zeitung La Presse (wo im August und September des Jahres 1862 in drei Lieferungen eine Folge von insgesamt zwanzig Prosagedichten erschien ${ }^{38}$ ) gerichteten - Dedikation voran, in dem er über die Entstehungsgeschichte seines Projekts, die damit verbundenen Intentionen und die Eigenart der so entstandenen Texte Auskunft gibt. Diese in Briefform gehaltene Widmung bildet also den deklarativen Paratext, der gemeinsam mit der Titelmarkierung die Funktion übernimmt, das neue Genre für die Leserschaft erkennbar zu begründen. Auf Grund ihrer Schlüsselrolle für die Gattungskonstitution - nicht zufällig stellten Baudelaires Nachlaßverwalter den Text später auch der erst postum erfolgenden Gesamtpublikation aller 50 Petits poèmes en prose (1869) voran ${ }^{39}$ - wird sie hier zur Gänze wiedergegeben:

37 Von nun an lassen sich bei der Publikation der Petits poimes en prose mehr oder minder klar definierte textuelle Ensembles erkennen, die eigens für den Druck in einer Zeitschrift zusammengestellt wurden; siehe in diesem Zusammenhang die übersichtliche Darstellung der Publikationsgeschichte bei Edward K. Kaplan: Baudelaire's Prose Poems. The Esthetic, the Ethical and the Religious in The Parisian Prowler. Athens/London: The University of Georgia Press 1990, S. 175-181. Nies zeigt sich deshalb überzeugt, "daß Baudelaire seine Petits Poimes en Prose [...] nicht als bloße Kollektion autonomer Einzelstücke, sondem als zusammengehöriges Ganzes verstanden haben " wollte: "Soweit sich die Entstehungsgeschichte der einzelnen Stücke verfolgen läßt, macht diese also zumindest ab 1861 eine planvolle, progressive Ausarbeitung des Gesamtwerkes in der ungefähren Reihenfolge der endgültigen Numerierung wahrscheinlich.« Fritz Nies: Poesie in prosaischer Welt. Untersuchungen zum Prosagedicht bei Aloysius Bertrand und Baudelaire, S. 268f. und 270. In neueren Arbeiten wird sogar die Ansicht vertreten, die von Baudelaire vorgesehene Anordnung der einzelnen Titel konstituiere ein "coherent ensemble» von Texten: "The prose poems' prepublication history [...] confirms this definitive arrangement and reinforces textual exegesis based on a sequential readingw; Edward K. Kaplan: Baudelaire's Prose Poems. The Esthetic, the Ethical and the Religious in The Parisian Prowler, S. ix. Diese These verfügt in jedem Fall über größere Plausibilität als die gegenteilige Annahme, die etwa von Beaujour vertreten wird. Seiner Aufassung nach seien die Petits poemes en prose snothing but a collection of discrete short pieces, whose only suggested coherence is [...] modal (spleen) and referential or topographical (de Paris)«; Michel Beaujour. Short Epiphanies: Two Contextual Approaches to the French Prose Poem. In: The Prose Poem in France. Theory and Practice, S. 44. Eine bereits vorbereitete vierte Lieferung mit weiteren sechs Prosagedichten blieb ungedruckt.

39 Neuere Editoren sind der Praxis von Asselineau und Banville weitgehend gefolgt. Auch die gegenwärtige Standardausgabe der Petits poìmes en prose in der »Bibliothèque de la Pléiadew präsentiert die Dedikation mit guten Gründen als integralen Bestandteil des Werks (vgl. Oc I, S. 275f.). 


\section{À Arsène Houssaye}

Mon cher ami, je vous envoie un petit ouvrage dont on ne pourrait pas dire, sans injustice, qu'il n'a ni queue ni tête, puisque tout, au contraire, y est à la fois tête et queue, alternativement et réciproquement. Considérez, je vous prie, quelles admirables commodités cette combinaison nous offre à tous, à vous, à moi et au lecteur. Nous pouvons couper où nous voulons, moi ma rêverie, vous le manuscrit, le lecteur sa lecture; car je ne suspends pas la volonté rétive de celui-ci au fil interminable d'une intrigue superflue. Enlevez une vertèbre, et les deux morceaux de cette tortueuse fantaisie se rejoindront sans peine. $\mathrm{Ha}$ chez-la en nombreux fraginents, et vous verrez que chacun peut exister à part. Dans l'espérance que quelques-uns de ces tronçons seront assez vivants pour vous plaire et vous amuser, j'ose vous dédier le serpent tout entier.

J'ai une petite confession à vous faire. C'est en feuilletant, pour la vingtième fois au moins, le fameux Gaspard de la Nuit, d'Aloysius Bertrand (un livre connu de vous, de moi et de quelques-uns de nos amis, n'a-t-il pas tous les droits à être appelé fameux?') que lidée m'est venue de tenter quelque chose d'analogue, et d'appliquer à la description de la vie modeme, ou plutôt d'une vie modeme et plus abstraite, le procédé qu'il avait appliqué à la peinture de la vie ancienne, si étrangement pittoresque.

Quel est celui de nous qui n'a pas, dans ses jours d'ambition, rêvé le miracle d'une prose poétique, musicale sans rythme et sans rime, assez souple et assez heurtée pour s'adapter aux mouvements lyriques de l'âme, aux ondulations de la rêverie, aux soubresauts de la conscience?

C'est surtout de la fréquentation des villes énormes, c'est du croisement de leurs innombrables rapports que naît cet idéal obsédant. Vous-même, mon cher ami, n'avez-vous pas tenté de traduire en une chanson le cri strident du Vitrier, et d'exprimer dans une prose lyrique toutes les désolantes suggestions que ce cri envoie jusqu'aux mansardes, à travers les plus hautes brumes de la rue?

Mais, pour dire le vrai, je crains que ma jalousie ne m'ait pas porté bonheur. Sitôt que j'eus commencé le travail, je m'aperçus que non seulement je restais bien loin de mon mysterieux et brillant modèle, mais encore que je faisais quelque chose (si cela peut s'appeler quelque chose) de singulièrement différent, accident dont tout autre que moi s'enorgueillirait sans doute, mais qui ne peut qu'humilier profondément un esprit qui regarde comme le plus grand honneur du poète d'accomplir juste ce qu'il a projeté de faire.

Votre bien affectionné,

C. B. (Oc I, S. 275f.)

Schon auf den ersten Blick ist erkennbar, daß Baudelaire in diesem Text nicht einfach in expositorischer Form Aussagen über das von ihm angestrebte neue Gattungsmodell macht. Vielmehr treibt er mit dem direkt angesprochenen Adressaten, den Lesern von La Presse sowie den späteren Rezipienten ein durchtriebenes Spiel, indem er gezielt falsche Fährten legt und seine tatsächlichen Absichten eher kaschiert als offenlegt. ${ }^{40}$ Dies zeigt sich zunächst an der Sprecherhaltung, die von den

40 Diese Verfahrensweise zeichnet im übrigen alle baudelaireschen Widmungstexte aus; vgl. hierzu Ross Chambers: Baudelaires Dedicatory Practice. In: SubStance 17 (1988), Nr. 2 (= Heft 56), S. 5-17. Es erscheint freilich kaum gerechtfertigt, die Widmungsepistel kurzerhand selbst als Prosagedicht anzusehen, wie das Johnson tut; vgl. Barbara Johnson: Défigurations du langage poétique. La seconde révolution Baulairienne, S. 28f. Im Anschluß daran 
üblichen Gepflogenheiten der Textsorte Dedikation signifikant abweicht. Auffällig ist besonders die merkwürdige "Ambivalenz von Ergebenheit und Selbstbewußtsein ${ }^{41}$, mit welcher der Schreiber dem Widmungsträger begegnet. Baudelaire war sichtlich darum bestrebt, seinem Gegenüber zu suggerieren, es existierten weitreichende Gemeinsamkeiten zwischen ihrer beider literarischen Bestrebungen. ${ }^{42}$ Dabei überschreitet sein mostentatives understatementk ${ }^{43}$ aber die Konventionen rhetorischer Bescheidenheitstopik so deutlich, daß sich die vermeintliche Anerkennung als "Scheinlob" ${ }^{44}$ enweist, hinter dem das Überlegenheitsbewußtsein des Verfassers sichtbar wird. Wie ein Blick auf den erwähnten Text Houssayes, La Chanson du Vitrier, zeigt, der als Beispiel für die angeblich von beiden imaginierte "prose poétique» genannt wird, erfüllt dieser gerade nicht das avisierte midéal der neuen Gattung, sondern kann bestenfalls als Versuch (ntenté $)$ gelten, der jedoch nichts anderes als eine - konventionelle - "prose lyrique« hervorgebracht hat. ${ }^{45}$ Indem die Petits poèmes

hat Chambers dann vorgeschlagen, die Dedikation an Houssaye "scomme un poème en prose sur le spoème en proserr zu deuten; Ross Chambers: Baudelaire et la prâtique de la dédicace. In: Saggi et ricerche di letteratura francese 24 (1985), S. 128. Die Formulierung kehrt wieder bei Sonya Stephens: Baudelaire's Prose Poems: The Practice and Politics of Irony. Oxford/New York: Oxford University Press 1999, S. 15. Auch Ortlieb spricht von wder strukturellen Übereinstimmung von Brieftext und Prosagedicht«; Cornelia Ortlieb: Poetische Prosa. Beiträge zur modemen Poetik von Charles Baudelaire bis Georg Trakl, S. 24.

41 Thorsten Greiner: Ideal und Ironie. Baudelaires Ästhetik der mmodernité، im Wandel vom Vers- zum Prosagedicht. Tübingen: Niemeyer 1993 (= mimesis 18), S. 219. In taktisch-pragmatischer Hinsicht diente die Dedikation der Prosagedichte ganz offensichtlich dazu, sich Houssayes Wohlwollen zu versichern, der dem ständig in Geldnöten steckenden Autor als eine Art Garant für eine lukrative Verbreitung seiner Texte und damit eine dauerhafte Sicherung seines Lebensunterhalts erschien. So läßt Baudelaire den Freund Auguste Poulet-Malassis zum Jahreswechsel 1861/62 unverblümt wissen: "[...] les poimes en prose, auxquels je travaille, paraitront de mois en mois moitié à L'Artiste, moitié à La Presse (vendus à Houssaye). Je voudrais trouver un moyen de tirer des Poèmes en prose la totalité approximative de leur valeur (en journal)«(C II, S. 213).

43 Johannes Hauck: Typen des französischen Prosagedichts. Zum Zusammenhang von moderner Poetik und Erfahrung, S. 43.

44 Thorsten Greiner. Ideal und Ironie. Baudelaires Ästhetik der modernitér im Wandel vom Vers- zum Prosagedicht, S. 219.

Schon der Titel »chansonu verweist auf die liedhafte Struktur dieses Textes, die vor allem an der zwölfmaligen refrainartigen Wiederholung des Ausrufs "Oh! vitrier!« erkennbar wird; vgl. den Abdruck in Oc I, S. 1309-1311. Dadurch zerfallt der Text strophenartig in elf kurze Abschnitte. Einzelne dieser Abschnitte weisen verschiedene Formen von Wiederholungen zur rhetorischen Intensivierung auf: Parallelismen - "[...] pas un enfant tapageur n’avait brisé une vitre de trente-cinq sous! pas un amoureux, en s'envolant la nuit par les toits, n'avait cassé un carreau de six sous! Pas une servante, pas une bourgeoise, pas une filletteu (Oc I, S. 1310) bzw. sà l'or, à l'amour, à la vanité، (Oc I, S. 1309) -, Rekurrenzen - wil s'évanouit; - oui, madame, il s'évanouit» (Oc I, S. 1310), "Allons! allons!، (Oc I, S. 1309) bzw. "Quatre heures, poursuivit-il, et je n'ai pas encore déjeuné! Quatre heuresk (ebd.) und Alliterationen - wcar je ne pus empêcher ses carreaux de casser" (Oc I, S. 1310) bzw. 
en prose aber mit dem Anspruch auftreten, erstmals jenen wmiracle» einer Prosa zu vollbringen, die musicale sans rythme et sans rime» ist, initiiert Baudelaire eine eigenartige Wettbewerbssituation zwischen sich selbst und dem Widmungsträger.

Unmittelbar greifbar wird die behauptete Konkurrenz dann dadurch, daß einer der für den Abdruck in La Presse vorgesehenen Texte unübersehbare intertextuelle Bezüge zu La Chanson du Vitrier enthält; ja das Prosagedicht Le Mawvais Vitrier kann geradezu als "une riposte malicieuse ${ }^{46}$ auf Houssayes ,Vorlager angesehen werden. Die »verborgene Ironie ${ }^{47}$ der Widmung beschränkt sich aber nicht allein auf Wortwahl und Argumentationsstruktur, sie erstreckt sich vielmehr bis in die rhythmische und klangliche Gestaltung hinein: So bezieht Baudelaire beispielsweise die Worte wrêverie u und wmanuscrit" phonetisch aufeinander, um ihren semantischen Gegensatz noch schärfer hervortreten zu lassen, oder er gestaltet die eigentliche Widmungsformel "j'ose vous dédier le serpent tout entier« als "(intern reimenden) Alexandriner ${ }^{48}$. Beide Male bedient er sich typischer Ausdrucksmittel lyrisierender Prosa und markiert so jene sprachlichen Verfahren, die er bestrebt war, bei seinen Petits poèmes en prose gerade nicht einzusetzen. ${ }^{49}$

»en vidant son verre« (ebd.). Es handelt sich hier im übrigen um sune forme que Chateaubriand avait exploitée dans les schansons indiennesı d'Alala [...] et qui est encore visible chez Aloysius Bertrand dans la répétition de certaines phrases comme dans la disposition typographique de ses fantaisies«; Graham M. Robb: Les Origines journalistiques de la prose poétique de Baudelaire. In: Les Lettres Romanes 44 (1990), S. 16. Formale Ähnlichkeiten bestehen denn auch weniger zu Baudelaires Prosagedicht Le Mawvais Vitrier als vielmehr zu dem in den Fleurs du mal enthaltenen Versgedicht Les Litanies de Satan mit seinem fünfzehnfachen Refrain Ô Satan, prends pitié de ma longue misère!« (Vgl. Oc I, S. 123-125.) Charles Baudelaire: Petits poëmes en prose. Édition critique par Robert Kopp, S. 181. Zu Baudelaires Prosagedicht vgl. Francis Heck: Le Maweais Vitrier. A Literary Transfiguration. In: Nineteenth Century French Studies 14 (1985/86), S. 260-268, Keiko Ido: Les expressions de la perversité chez Baudelaire. La méthode d'Edgar Poe et la genèse du Manuais Vitrier. In: Études de langue et de littérature françaises 46 (1985), S. 52-67, Anthony Wall: Parody without Markers: Baudelaire's Le Mawvais Vitrier. In: Clive Thomson (Ed.): Essays on Parody. Toronto: Victoria University 1986 (= Monographs, Working Papers and Prepublications of the Toronto Semiotic Circle 4), S. 60-75, und Richard D.E. Burton: Destruction as Creation: Le Mawrais Vitrier and the Poetics and Politics of Violence. In: Romanic Review 83 (1992), S. 299-306. Stephens sieht dit Widmung insgesamt als ma parody of influence performed by a further parody of the prose poetry genre's referential practices; Sonya Stephens: Baudelaire's Prose Poems: The Practice and Politics of Irony. Oxford/ New York: Oxford University Press 1999, S. 13.

47 Thorsten Greiner: Ideal und Ironie. Baudelaires Ästhetik der modemité im Wandel vom Vers- zum Prosagedicht, S. 216.

48 Ebd., S. 219. Gleichfalls mit einem solchen, wie eine "Versruinew in der sie umgebenden Prosa stehenden Alexandriner endet Les Veutes, Hans-Jost Frey: Verszerfall, S. 18.

49 Murphy spricht in diesem Zusammenhang denn auch von einer mredéfinition baudelairienne du poéme en prose«; Steve Murphy: Logiques du demier Baudelaire. Lectures du Spleen de Paris. Paris: Honoré Champion 2003 (= Romantisme et modernités 69), S. 349. 
Eigenartig berührt auch die ungenierte Anpreisung der Prosagedichte für die Erfordernisse der periodischen Presse - zumal Baudelaire sich andernorts wiederholt sehr unzufrieden über eine stückweise Veröffentlichung seiner Texte zeigte, auf die er aber aus ökonomischen Gründen angewiesen war. ${ }^{50} \mathrm{Zwar}$ erscheint es zunächst im Hinblick auf den Verwendungszweck der Texte verständlich, wenn der Autor deren Selbständigkeit und Kürze hervorhebt und damit auf ihre besondere Eignung für den sukzessiven Abdruck in Zeitschriften aufmerksam macht, ${ }^{51}$ doch wirkt die Emphase, mit der die Petits poèmes en prose sowohl in produktions- wie in distributions- und rezeptionsästhetischer Hinsicht als nachgerade ideale Verwertungsform hingestellt werden - madmirables commodités [...] à tous, à vous, à moi et au lecteur« -, reichlich übersteigert. Zudem wird dabei auch noch die logische Konsistenz der Argumentation geopfert. Wenn nämlich Baudelaire kurzerhand behauptet, das von ihm zum Abdruck vorgesehene Werk habe "ni queue ni tête«, weil die einzelnen Abschnitte nach Belieben umstell- und austauschbar seien, dann erteilt er damit allen Vorstellungen von einem klar gegliederten Textzusammenhang mit festgelegtem Anfang und Ende eine Absage. ${ }^{52}$ Demnach dürfte kein hierarchisch geordneter Wechselbezug der Textbausteine existieren, vielmehr müßten diese als gleichberechtigte Elemente angesehen werden, deren Anordnung lediglich zufälligen und damit veränderbaren Anlässen entspringt.

Zugleich aber enthält die Widmung, die zunächst von einer Rhetorik der Fragmentierung bestimmt ist, im ersten wie im letzten Satz des Anfangsabsatzes Begriffe, die klar auf Ganzheit verweisen. ${ }^{53}$ Sowohl der Ausdruck wun petit ouvrageu als auch die Metapher von der sserpent tout entier" dementieren denn auch die Rede

50 So erklärt ex in einem undatierten Brief an Poulct-Malassis von August oder September 1862 , daß er seit längerem einen Weg suche, wd'abundonner à tout jamais te système de fragmentation dans ks journawx qui me fait tont souffrim (C II, S. 256).

51 Der Hinweis auf die mintrigue superflue» zielt in diesem Zusammenhang auf die Mitte des 19. Jahrhunderts überaus beliebte Gattung des Feuilletonromans, dessen bereits auf die Erfordernisse der Joumalpublikation und das Leseverhalten breiter Schichten zugeschnittener Präsentationsmodus durch die von Baudelaire neugeschaffene Gattung noch überboten werden soll. Da die Prosagedichte auf das Element durchgehender Handlung verzichteten, seien sie der auf Fortsetzung angewiesenen Struktur des Romans publikationstechnisch überlegen. Diesen spielerisch-polemischen Bezug auf die Gattung Roman übersieht Margery Evans, wenn sie die Petits poèmes en prose in die Nähe der erzählerischen Digressionstechnik Sternes zu rücken versucht; vgl. ihren unergiebigen Aufsatz: Lawrence Steme and $L$ Spleen de Paris. In: French Studies 42 (1988), S. 165-176.

Teile der Forschung sehen denn auch die Diskontinuität der Petits poimes en prose als erwiesen an. So meint etwa Thélot: "Il ne faut pas tenter de composer Le Spleen de Paris [...]. Ce recueil n'est pas un livre, et ne se comprend lui-même qu'en tant que désécriturew; Jérôme Thélot: Baudelaire. Violence et poésie. O.O. [Paris]: Gallimard 1993 (= Bibliothéque des Idées), S. 135. Tatsächlich sind die einzelnen Texte aber sukzessiv durchnumeriert.

53 Dementsprechend hatte Baudelaire auch in seinen Notes noutelles sur Edgar Poe unmißverständlich geäußert, s'Unitéu sei sla condition vitale de toute ceuvre d'art" (Oc II, S. 332). 
von der beliebigen Teilbarkeit. Überhaupt erweist sich die Metapher von der Schlan$\mathrm{ge}^{54}$ als inadäquat, wenn damit die Möglichkeit willkürlicher Neuorganisation der Einzelelemente zum Ausdruck gebracht werden soll. Wie die Erwähnung der nvertèbres« zeigt, weiß Baudelaire natürlich, daß Schlangen zum Stamm der Wirbeltiere gehören und damit biologisch relativ hoch entwickelte Lebewesen darstellen, deren Einzelteile nicht für sich lebensfähig sind. Möglich wäre dies allenfalls bei einer primitiven, weil wenig ausdifferenzierten Lebensform wie einem Wurm. Auch läßt sich von einer Schlange gerade nicht sagen, daß sie mni queue ni tête« besitze. Sie gibt im Gegenteil vielmehr das Muster einer linearen Struktur ab, wobei deren Geradlinigkeit durch die gewundene Fortbewegungsweise des Tiers im gleichen Zug aber auch wieder konterkariert wird.

Am ehesten kann die Schlange deshalb als Metapher für die spannungsvolle Einheit zweier Gegensätze gelten. ${ }^{55}$ Sie fügt sich damit in ein Bildfeld ein, das innerhalb der Petits poìmes en prose vor allem in dem Franz Liszt gewidmeten Text $L$ Thyrse entfaltet wird. ${ }^{56}$ Ein Thyrsusstab ist nach Baudelaire durch seine funktionale und materiale Doppelnatur gekennzeichnet: „Selon le sens moral et poétique, c'est un emblème sacerdotal [...]. Mais physiquement ce n'est qu'un bâton« (Oc I, S. 335). Doch nicht erst durch seinen Gebrauch, bereits durch seine optische Gestalt erscheint er als Verbindung von Gegensätzen, die sich gewöhnlich ausschließen. ${ }^{57}$ So läßt er sich beschreiben als "[...] un pur bâton, [...] sec, dur et droit. Autour de ce bâton, dans des méandres capricieux, se jouent et folâtrent des tiges et des fleurs, celles-ci si-

54 Mit dem Bild der Schlange greift Baudelaire im übrigen auf einen eingeführten Topos der französischen Literatur zun̈̈ck. Pichois hat einschlägige Belege bei Hugo, Sainte-Beuve, Nerval, Lamartine und Latouche aufgeführt; vgl. Oc I, S. 1308.

De George bildet in seinem Versuch, die Fortbewegungsart der Schlange als Muster der Textanordnung zu deuten - the poems move in undulating waves" -, Baudelaires komplexe Metapher recht naiv auf die Werkstruktur ab; Fernande M. de George: The Structure of Baudelaire's Petits poémes en prase. In: L'Esprit Créateur 13 (1973), S. 149.

Intertextuelle Bezüge bestehen offenkundig auch zu den Fleurs du mal, wo in zwei Gedichten das Schreiten einer Frau mit der Bewegung einer sich um einen Stab ringelnden Schlange verglichen wird. So heißt es in dem unbetitelten Gedicht mit der Nummer XXVII: "Avec ses vêtements ondoyants et nacrés / Même quand elle marche on croirait qu'elle danse, / Comme ces longs serpents que les jongleurs sacrés / Au bout de leurs bâtons agitent en cadence. (Oc I, S. 29) Und in dem darauffolgenden Text mit der Überschrift $L$ Serpent qui danse ist zu lesen: "À te voir marcher en cadence, / Belle d'abandon, / On dirait un serpent qui danse / Au bout d'un bâton." (Oc I, S. 30)

In den Paradis artifficels weist Baudelaire darauf hin, daß de Quincey sein Denken einmal mit einem Thyrsusstab verglichen habe: wun thyrse, simple bâton qui tire toute sa physionomie et tout son charme du feuillage compliqué qui l'envelopper (Oc I, S. 444; vgl. auch ebd., S. 515). Siehe in diesem Zusammenhang auch Melvin Zimmerman: La Genèse du symbole du thyrse chez Baudelaire. In: Bulletin Baudelairien 2 (1966), Heft 1, S. 8-11, und Marc Eigeldinger: À propos de l'image du thyrse. In: Revue d'histoire littéraire de la France 75 (1975), S. 110-112. 
nueuses et fuyardes, celles-là penchées comme des cloches ou des coupes renversées.« (Oc I, S. 336) Auf Grund dieser ihm innewohnenden Widerspruchstruktur fungiert der Thyrsusstab für Baudelaire als eine Art Dingsymbol - nicht nur für die sétonnante dualité火, die Mensch und Kunst fundamental prägt, ${ }^{58}$ sondern auch für die gattungslogische Dialektik des poème en prose. Als solches legt er auch die komplexe Struktur dieses Kommunikationstyps offen: So wie der Thyrsus "physiquement« nur ein hölzerner Stab ist, der erst im Rahmen seines Einsatzes eine weit über seine Materialität hinausreichende symbolische Funktion erhält, so erlangen auch die Textsorten, aus denen sich die Petits poèmes en prose konstituieren, erst durch den ungewohnten Kontext ihrer Verwendung jenen veränderten Status, der sie dem Hypergenre Prosagedicht zuordnet. Und auch die spannungsvolle Verbindung der beiden dichotomischen literarischen Ausdrucksmodi wird im Thyrsusstab im direkten Wortsinn greifbar: »les connotations étymologiques des notions mêmes de vers et de prose renvoient, précisément, á la droite et à l'arabesque: PROSE: de prosa oratio, 'discours qui va en droite lignec; VERS: de vertere, stournerer ${ }^{59}$.

Überhaupt fällt auf, daß sich Baudelaire in seiner Widmung an Arsène Houssaye einiger Metaphern bedient, die ähnlich auch bei der Charakterisierung des Thyrsusstabs begegnen; so spricht er einerseits vom $n$ fil interminable d'une intrigue superflue«, andererseits von den »ondulations de la rêverie«. Nach eigenem Bekenntnis ist er auf der Suche nach einem textucllen Modell, das die beiden Pole ssouple et [...] heurtée« miteinander verschmelze; das Ergebnis seiner Bestrebungen stellen die Petits poìmes en prose dar. Die Schlange also, die Baudelaire als Bild für das Werkganze präsentiert, ist in Wirklichkeit sinnvoll nur als Metapher für die Gattungsstruktur der einzelnen Texte zu verstehen. ${ }^{60}$ Deshalb geht es auch nicht - wie behauptet - um die Selbständigkeit der Einzelteile, sondern vielmehr - wie sich aus den intertextuellen Bezügen ergibt - um die Frage, wie eine innige Verbindung von Gegensätzen möglich wird. Weil das Prosagedicht wie die Schlange, die linear und mäandrisch gewunden zugleich ist, einander scheinbar widersprechende Merkmale miteinander verbindet, ${ }^{61}$ fällt im Endeffekt die logische Berechtigung für eine Unterscheidung zwischen »tête et queue« fort. Berücksichtigt man schließlich den mit der Schlange

58 Stephens sieht das Prosagedicht Le Thyrse deshalb auch als martistic programme« Baude laires; Sonya Stephens: Baudelaire's Prose Poems: The Practice and Politics of Irony, S. 42.

59 Barbara Johnson: Défigurations du langage poétique. La seconde révolution baudelairienne, S. 176.

60 In einem Entwurf zu seinem Widmungstext nennt Baudelaire seine Prosagedichte ein wouvrage tenant de la vis et du kaléidoscope« (Oc I, S. 365). Die Kaleidoskop-Metapher steht in diesem Zusammenhang für Fragmentarizität, Dynamik und Diskontinuität. Vgl. hierzu die von Kolesch herausgearbeiteten „Bedeutungsfelder der Metapher vom Kaleidoshop» (S. 23); Doris Kolesch: Das Schreiben des Subjekts. Zur Inszenierung ästhetischer Subjektivität bei Baudelaire, Barthes und Adorno, S. 23-25.

61 In Baudelaires 1861 erschienenem Versgedicht L'Atertisseur erscheint die Schlange als personifizierte innere Widerspruchsinstanz. 
gegebenen Verweis auf den biblischen Paradiesesmythos, so stellt die Überreichung der Petits poèmes en prose an Houssaye einen symbolischen Seduktionsakt dar, bei dem Baudelaire, der Schöpfer der textuellen "Schlange«, als diabolische Gestalt erscheint, die mit ihrem Werk den Adressaten - und das ist hier vor allem der Leser - zum bislang verborgenen, weil verbotenen Wissen über das Geheimnis der "prose poétique verführt. ${ }^{62}$ Es hat deshalb den Anschein, als ob Baudelaires Versicherung beliebiger Disponierbarkeit eher ein rhetorisches Ablenkungsmanöver darstellt, das paradoxerweise gerade das Gegenteil garantieren sollte, nämlich die unbehinderte Akzeptanz der Texte in der von Baudelaire geplanten Anzahl und Sukzession. ${ }^{63}$

In Fortführung der vexierbildhaften "Zweideutigkeit ${ }^{64}$ seiner Argumentation verweist Baudelaire auf ein mmysterieux et brillant modèle«, das ihm als Orientierung bei seiner Suche gedient habe: die 1842 erschienene Sammlung lyrisierender Kurzprosa Gaspard de la Nuit. Fantaisies à la manière de Rembrandt et de Callot von Aloysius Bertrand. Der Hinweis auf dieses Werk hat große Teile der Forschung dazu bewogen, Bertrand als eigentlichen Inventor des Prosagedichts zu verstehen und mit ihm die Geschichte der Gattung beginnen zu lassen (siehe hierzu Kapitel I/2). Doch wie der Blick auf den Wortlaut der Widmung zeigt, ist dieser mitnichten jenes Vorbild, dem Baudelaire dann mehr oder weniger treu gefolgt ist. Zwar spricht Baudelaire zunächst noch davon, daß er »quelque chose d'analogue" geschaffen habe, dies korrigiert er freilich am Ende dahingehend, es handle sich dabei in Wirklichkeit doch um »quelque chose [...] de singulièrement différentw. Der pittoresken »vie anciennew Bertrands stellt er in aller Deutlichkeit die abstrakte wvie moderne" gegenüber, den auf die bildende Kunst zielenden Begriffen "peinture und "pastiche ${ }^{65}$ setzt er die nüchterne Form der mdescription entgegen. ${ }^{66}$ Die schließlich von ihm vorgebrachte Rechtfertigung, es sei immerhin seine Intention gewesen, Bertrand nachzueifern, auch wenn er sich jetzt eingestehen müsse, daß ihm dies nicht gelungen sei, kann

62 Die Metaphorik wird allerdings überstrapaziert, wenn man, wie Kolesch, soweit geht, das Prosagedicht pauschal als meine Form nach dem Sündenfalla zu bezeichnen; Doris Kolesch: Das Schreiben des Subjekts. Zur Inszenierung ästhetịscher Subjektivität bei Baudelaire, Barthes und Adomo, S. 223, Anm. 40. Und tatsächlich lieferte Baudelaire auch eine von ihm vorbestimmte Sequenz von durchnumerierten Texten, die an ein zyklisches Modell erinnert, vgl. hierzu unten.

64 Thorsten Greiner: Ideal und Ironie. Baudelaires Ästhetik der modemité» im Wandel vom Vers- zum Prosagedicht, S. 220. Dieser Begriff fält im Zusammenhang mit dem Gaspard de la nuit in einem Brief an Houssaye von Weihnachten 1861; vgl. C II, S. 208.

66 "Die Beschreibung des modernen Lebens abstrahiert vom Malerischen, obgleich sie oder vielmehr gerade weil sie - die Erfahrung einer unüberschaubaren Vielheit des Lebens voraussetzt." Raimund Theis: Zur Sprache der »cité in der Dichtung. Untersuchungen zum Roman und zum Prosagedicht (Realismusstudien, 1. Teil). Frankfurt a.M.: Klostermann 1972 (= Analecta Romanica 33), S. 137. 
nicht anders denn als ironisch verstanden werden. ${ }^{67}$ Bertrand erweist sich für Baudelaire eher als ein "point de départw ${ }^{68}$. Anstatt das Verfahren dieses Vorläufers nachzuahmen, vermißt Baudelaire mit seinen Petits poèmes en prose gerade den Abstand zu ihm. Der Gaspard de la nuit, der anfangs noch als Gegenstand eines Imitationswunsches erscheint, ist schließlich nicht mehr als die Folie, vor der er sein eigenes Autonomiestreben wirkungsvoll inszeniert: "Je faisais autre chose que ce que je voulais imiter" (Oc I, S. 365), heißt es selbstbewußt im Entwurf der Widmung. Mit dem Verweis auf Bertrand kaschiert Baudelaire denn auch das eigentliche Skandalon, das darin besteht, daß er mit dem poème en prose eine Gattung präsentiert, die nicht nur keinen Vorläufer in der Geschichte der abendländischen Poetik hat, sondern die sich auch gänzlich außerhalb jeder normativen Ästhetik bewegt. Sobald man freilich die nur scheinbar traditionsstiftenden Verweise auf Houssaye und Bertrand als argumentative Finten durchschaut, wird das baudelairesche Prosagedicht mit einem Mal als das erkennbar, was es tatsächlich ist: eine synthetische Gattung, die ihren konstruierten Charakter auch noch ausstellt. ${ }^{69}$ Die Absage an die Poesie manifestiert sich hier auch in einer Verabschiedung des Prinzips der spoiesis‘ zugunsten des ımodernen، Prinzips der stechnes.

Alles in allem weist die Zueignung an Houssaye also unverkennbar einen »Doppelcharakter« auf: Sie ist sironisch-ambivalente Widmung« und "programmatisches Vorwort $^{70}$ zugleich. Die "spielerisch-paradoxe Begründung« der Gattung gehorcht

67 Thélot hat darauf hingewiesen, daß dies durchaus kein Einzelfall in Baudelaires Werk ist, sondern vielmehr ein Verfahrensmuster darstellt mtoujours l'imitateur manque son imitation«; Jérôme Thélot: Baudelaire. Violence et poésie, S. 454. Nach Greiner kann die Differenz zwischen Absicht und Ergebnis geradezu als konstitutiv für die baudelairesche "Dialektik des Begehrens« angesehen werden, die dadurch charakterisiert ist, daß fremdbestimmte Orientierung an einem Ideal und eigenes Autonomiestreben konfligierend aufeinandertreffen und so zur "Produktionsdynamik von Kunst" werden; Thorsten Greiner. Ideal und Ironie. Baudelaires Ästhetik der mmodemité« im Wandel vom Vers- zum Prosagedicht, S. 3.

68 Als einen solchen bezeichnet Baudelaire den Gaspard de ka nuit sowohl im bereits erwähnten Brief von Weihnachten 1861 als auch im Entwurf der Widmung an Houssaye spricht; vgl. C II, S. 208, und Oc I, S. 365. Auch die - in der Widmungsvorrede nicht erwähnte - Tatsache, daß Houssaye Bertrand in seinem Werk Voyage à ma fenetre (1851) überschwenglich gelobt hatte, rückt diesen in ein wenig günstiges Licht. Bürgers Feststellung: "Das Neue an der Ästhetik Baudelaires ist gerade die Herstellung einer Diskontinuität« bewahrheitet sich also auch an der Gattungsstruktur der Petits poimes en prose; Peter Bürger: Klassizität und Modeme. Zur Allegorie bei Baudelaire. In: Romanistische Zeitschrift für Literaturgeschichte / Cahiers d'histoire des littératures romanes 9 (1985), S. 130.

70 Johannes Hauck: Typen des französischen Prosagedichts. Zum Zusammenhang von modemer Poetik und Erfahrung, S. 41. Hauck weist zu Recht auch darauf hin, daß es eine Reihe von manderen poetologischen und theoretischen Texten Baudelaires [gibt], die, frei von einem ironischen Adressatenbezug, wesentliche Aussagen der Dédicace stützetrw; ebd. 
dabei aber nur einer »Logik scheinbarer Evidenz ${ }^{71}$, denn was eigentlich ein Manifest darstellen müßte, stellt sich schließlich als raffiniertes Verwirrspiel mit dem Leser heraus. Dem "goût du travestissement et du masque» (Oc I, S. 291) folgt Baudelaire auch in der Anlage und den einzelnen Texten seines Werks selbst. So lassen sich - entgegen der Beteuerung in der Dedikation - in der Gesamtheit der Petits poèmes en prose durchaus Ansätze einer sequentiellen Strukturierung erkennen. Nicht nur der erste (L'Étranger) und der letzte Text (Les Bons Chiens) des Bandes sind gezielt auf ihre einleitende bzw. abschließende Funktion hin konzipiert, auch die Durchnumerierung der Prosagedichte mit römischen Ziffern legt eine fortlaufendlineare Lektüre nahe. $\mathrm{Ob}$ und inwieweit man aber tatsächlich von einer zyklischen Werkgestalt sprechen kann, ${ }^{72}$ werden erst weitere Untersuchungen zu Aufbau und Struktur der Sammlung zeigen. In jedem Fall unterscheidet sich die Präsentation der Petits poèmes en prose merklich von jener der Versgedichte in den Fleurs du mat.

Während Les Fleurs du Mal durch einen strengen tektonischen Aufbau gekennzeichnet sind - der Gedichtband besteht aus sechs thematisch zusammengehörigen Zyklen - und auch der Gaspard de la Nuit von Aloysius Bertrand in sechs Bücher gegliedert ist, dic jeweils eine motivische Einheit bilden, gibt es eine solche Gliederung in den Petits Poimes en Prose nicht. ${ }^{73}$

Der vielfachen formalen und thematischen Binnengliederung von Baudelaires einzigem Lyrikband, die schon die Zeitgenossen mit dem Begriff der \Architektur metaphorisch zu erfassen versuchten, ${ }^{74}$ steht das schlichte numerische Prinzip der Prosagedichte gegenüber. Wenn der Autor in der Widmung an Houssaye die »Isolierbar-

71 Thorsten Greiner: Ideal und Ironie. Baudelaires Ästhetik der mmodernité im Wandel vom Vers- zum Prosagedicht, S. 217.

72 Zur zyklischen Form von Baudelaires Prosagedichten vgl. insbesondere Fritz Nies: Poesie in prosaischer Welt. Untersuchungen zum Prosagedicht bei Aloysius Bertrand und Baudelaire, S. 259--287, sowie ders.: Der Poet als Flaneur und der wzyklische» Charakter der Petits Poimes en Prose. In: Baudelaire. Hrsg. von A. Noyer-Weidner. Darmstadt: Wissenschaftliche Buchgesellschaft 1976 (= Wege der Forschung 283), S. 365-393.

73 Margot Kruse: Motive zwischen Tradition und Innovation in den Petits Poemes en Prose von Baudelaire. In: Gattungsinnovation und Motivstruktur. Bericht über Kolloquien der Kommission für literarische Motiv- und Themenforschung. Teil 1. Hrsg. von Theodor Wolpers. Göttingen: Vandenhoeck \& Ruprecht 1989 (= Abhandlungen der Akademie der Wissenschaften in Göttingen. Philologisch-historische Klasse. Dritte Folge 184), S. 151.

74 Jules Barbey d'Aurevilly sprach in einem Artikel über die Fleurs du mal von. der warchitecture secrites (Oc I, S. 1196) des Werks. Zu fast normativer Gültigkeit gelangte diese Ansicht dann durch Friedrich, der die Fleurs du mal als das warchitektonisch strengste Buch der europäischen Lyrik" mneben Petrarcas Canzoniere, Goethes Westöstichem Divan und Guilléns Canticar bezeichnet hat, Hugo Friedrich: Die Struktur der modemen Lyrik. Von der Mitte des neunzehnten bis zur Mitte des zwanzigsten Jahrhunderts [1956]. Mit einem Nachwort von Jürgen v. Stackelberg. Reinbek: Rowohlt 1985 (= rowohlts enzyklopädie 420), S. 39. Eine ergiebige Einzeluntersuchung zum Aufbau von Baudelaires Gedichtsammlung hat Mossop vorgelegt; vgl. D.J. Mossop: Baudelaire's Tragic Hero. A Study of the Architecture of Les Fleurs du Mal. Oxford: Clarendon Press 1961. 
keit des Einzelnen« betont, so ist dies im wesentlichen als Hinweis darauf zu verstehen, daß die Sammlung seiner Prosatexte seine Ablösung des Architekturprinzips aus den Fleurs du mok ${ }^{75}$ vollzieht. Das Verhältnis der Fleurs du mal zu den Petits poèmes en prose ist denn auch nicht einfach als antagonistischer Gegensatz zu denken, sondern vielmehr als komplexe Konflikt- und Überbietungsstruktur. ${ }^{76}$

So enthält die Erstausgabe von Baudelaires Lyriksammlung Fleurs du mal (1857) insgesamt 100 Texte - also exakt jene Anzahl, die der Autor auch für seine Petits poìmes en prose vorgesehen hat. Darüber hinaus verweisen der Titel des quantitativ bei weitem größten Abschnitts der Sammlung, "Spleen et idéal", sowie die Überschrift "Spleen«, welche insgesamt vier Versgedichte tragen, unverkennbar auf die Kurzprosa, die Baudelaire längere Zeit bekanntlich »Le Spleen de Paris“ genannt hat. Es gibt darüber hinaus zahlreiche motivverwandte Texte, die einen Vergleich geradezu herausfordern. ${ }^{77}$ Das ebenfalls neu hinzugekommene letzte Gedicht der zweiten Edition schließlich, Le Voyage, mündet in einen wüber sich hinausweisenden Schluß«, läßt sich doch die letzte Zeile dieses Textes auch als mehr oder minder deutliche »Ankündigung ${ }^{78}$ der Prosagedichte verstehen: »Au fond de l'Inconnu pour trouver du nouveau! (Oc I, S. 134)

Innerhalb der Sammlung der fünfzig Petits poèmes en prose fällt zunächst die - für den Kommunikationstyp Hypergenre typische - formale Vielfalt der Texte auf: Es gibt Prosagedichte in der Er- und in der Ich-Form, solche, die als Dialog gestaltet sind (L'Étranger, Perte d'auréole), und solche mit monologischer Struktur (La Femme sauvage et la petite-maitresse), es begegnen Anreden an den Leser (Le Joujou du pautre), gebetartige Anrufungen ( $A$ une heure du matin, Mademoiselle Bistouri), Dedikationstexte mit direkter Anrede (Le Thyrse), Geschichten mit Anekdotencharakter (Le Miroir)

75 Thorsten Greiner: Ideal und Ironie. Baudelaires Ästhetik der mmodernitér im Wandel vom Vers- zum Prosagedicht, S. 218.

76

In zahlreichen brieflichen Äußerungen hat Baudelaire beide Werkprojekte in unmittelbaren Bezug zueinander gesetzt. So definiert er Funktion und Verwendungszweck seiner Prosagedichte programmatisch in einer "Note pour M. Hippolyte Garbierı, die einem Brief an Narcisse Ancelle vom 6.2.1866 beilag: "LE SPLEEN DE PARIS, pour faire pendant aux Fleurs $d u$ mal. (En prose.) " (C II, S. 591) - eine Formel, die sich in der Korrespondenz vielfach variiert wiederfindet (vgl. die Schreiben an Namslauer von Ende Mai bzw. Anfang Juni 1863, an Victor Hugo vom 17.12.1863, an Jules Lemer vom 6.6. bzw. vom 9.8.1865 und an Narcisse Ancelle vom 12. sowie vom 18.1.1866). Aufschlußreich ist auch der Brief an Jules Troubat vom 19.2.1866, in dem der Autor über die Pesits prèmes en prose bemerkt: "En somme, c'est encore Les Fleurs du mal, mais avec beaucoup plus de liberté, et de détail, et de raillerie.« (C II, S. 615) Köhler sieht die Petits poèmes en prose als meine Art Potenzienung dessen [...], was auch die Verslyrik der Fleurs du Mal anstrebta; Erich Köhler: Vorlesungen zur Geschichte der Französischen Literatur, [Bd. 11,] S. 37. Das bekannteste Beispiel hierfür sind das Versgedicht La Chevelure und der Prosatext Un bémisphère dans une chevelure.

78 Thorsten Greiner: Ideal und Ironie. Baudelaires Ästhetik der mmodernité im Wandel vom Vers- zum Prosagedicht, S. 202 und 203. 
und solche mit Märchenstruktur (Les Dons des fées), ${ }^{79}$ wobei fast allen Prosastücken eine gewisse allegorische Parabolik gemeinsam ist. ${ }^{80}$ Auch in ihrem Umfang unterscheiden sich die einzelnen Texte stark: Am umfangreichsten sind Portraits de maîtresses und Une mort bérö̈que mit - Bestandteile von Komposita jeweils einzeln gezählt deutlich über 1500 bzw. 1000 Wörtern, während der kürzeste Text Le Miroir gerade einmal 87 Wörter umfaßt.

Auch wenn man nicht so weit zu gehen braucht wie Nies, für den die "Abfolge» der Prosagedichte eine formale "Spiegelung ${ }^{81}$ der Erfahrungen eines Flaneurs darstellt, wird man doch davon ausgehen können, daß die Wirklichkeitsausschnitte, welche die Petits poèmes en prose präsentieren, grundsätzlich der Wahrnehmungsweise eines "promeneur solitaire« (Oc I, S. 291) entsprechen: Dem »Flaneur ist einmal der dauernde Ortswechsel eigentümlich, und zum andern, daß sein Umherstreifen ohne bestimmtes Ziel bleibt ${ }^{82}$. Rechnet man das "Interesse am Fremden ${ }^{83}$ hinzu, so erscheint Flanerie geradezu mals Form der ästhetischen Erfahrung “ ${ }^{84}$. Erfahrungsraum des Flaneurs ist die Großstadt. ${ }^{85}$ Schon im Salon de 1846 hatte Baudelaire festgestellt:

79 Andringa weist in diesem Zusammenhang zu Recht hin auf die für das Prosagedicht charakteristische stendency to modify, parody or invert conventional short prose genres that used to represent moral or didactic principles: legends, parables, fairy tales, biblical texts, prayers and sermonse; Els Andringa: The Art of Being Anti-Conventional. The Case of the Prose Poem. In: The Search for a New Alphabet. Literary Studies in a Changing World. In Honor of Douwe Fokkema. Ed. by Harald Hendrix, Joost Kloek, Sophie Levie, Will van Peer. Amsterdam/Philadelphia (Philadelphia): John Benjamins Publishing Co. 1996, S. 4. Schon im Salon de $18+5$ weist Baudelaire darauf hin, wque l'allégorie est un des plus beaux genres de l'art" (Oc II, S. 368). Und in den Paradir antificiels heißt es, die Allegorie sei ein "genre si spirituel, [...] qui est vraiment l'une des formes primitives et les plus naturelles de la poésie" (Oc I, S. 430). Vgl. in diesem Zusammenhang Hans Robert Jauß: Baudelaires Rückgriff auf die Allegorie. In: Formen und Funktionen der Allegorie. Symposion Wolfenbüttel 1978. Hrsg. von Walter Haug. Stuttgart: Metzler 1979 (= Germanistische Symposien. Berichtsbände 3), S. 686-700. Greiner hat plausibel gemacht, daß Baudelaire das allegorische Verfahren vor allem auf Grund seines "Differenzcharakters« schätzte: "Gegenüber der im Symbol offenen Grenze zwischen Bild und Sinn [...] hat die Trennung der Bereiche in der Allegorie, die das Eigentliche uneigentlich sagt, dic Struktur der Ironie. " Thorsten Greiner: Ideal und Ironie. Baudelaires Ästhetik der mmodernité im Wandel vom Vers- zum Prosagedicht, S. 67. Carpenter hat für diese 'Textform schließlich den Begriff der mironic allegory“ geprägt; Scott Carpenter: Acts of Fiction. Resistance and Resolution from Sade to Baudelaire. University Park (Pennsylvania): The Pennsylvania State University Press 1996 (= Penn State Studies in Romance Literatures), S. 138.

Fritz Nies: Poesie in prosaischer Welt. Untersuchungen zum Prosagedicht bei Aloysius Bertrand und Baudelaire, S. 276. Ebd., S. 267.

84 Eckhardt Köhn: Straßenrausch. Flanerie und kleine Form. Versuch zur Literaturgeschichte des Flaneurs bis 1933, S. 64.

85 Neben dem öffentlichen Raum der Stadt begegnet als Schauplatz aber auch die eigene 
"La vie parisienne est féconde en sujets poétiques et merveilleux. Le merveilleux nous enveloppe et nous abreuve comme l'atmosphère; mais nous ne le voyons pas.« (Oc II, S. 496) Die Wahrnehmung des Flaneurs richtet sich freilich nicht auf die Erkennungszeichen und touristischen Ziele der Stadt, sondern bevorzugt auf Orte wie Vorstädte, entlegene Straßen, Jahrmärkte, Nachtlokale (aber auch Cafés und Parks), an denen sdem Beobachter eine gesellschaftlich verdrängte Sphäre der urbanen Realität ${ }^{86}$ begegnet: Bettler, Prostituierte, Arme und Geisteskranke. Doch auch die übrigen Personen, die in den Prosagedichten auftreten - u.a. Exzentriker, Straßenhändler, alte Menschen -, zeichnen sich häufig durch ihre soziale Randständigkeit aus. Das Interesse an diesen Figuren speist sich jedoch nicht aus karikativem Mitleid, es entspringt vielmehr deren wästhetischer Differenzqualität ${ }^{87}$. Im Salon de 1846 spricht Baudelaire fasziniert von den milliers d'existences flottantes qui circulent dans les souterrains d'une grande ville (Oc II, S. 495). Nur der Blick auf die wfoule de parias« (Oc I, S. 293) und die séclopés de la vie« (Oc I, S. 292) - Menschen also, die wals emblematische Verdichtung urbaner Existenzweisen ${ }^{88}$ fungieren -, vermag denn auch jene verborgene Poesie moderner Großstadtrealität zu entdecken, von der Baudelaire so besessen war.

Die Wahrnehmung dieser Personen bleibt freilich immer subjektiv. So schnell, wie sie in das Blickfeld des beobachtenden Subjekts geraten, so schnell verschwinden sie auch wieder in der gesichtslosen Masse. Folgerichtig erscheint dem Ich »die Menge als Inbegriff der Möglichkeiten, seine Phantasie zu entfalten «" ${ }^{89}$ ja sie fungiert geradezu als Mittel zur Bewußtseinserweiterung, darin den Drogen Wein und Haschisch analog. Die Großstadt erlaubt dem »promeneur solitaire« eine »communion« (Oc I, S. 291) mit der Menge, ohne daß dieser dabei sein Ich aufgeben muß. Die Menge ist nicht nur Bühne für den Einzelnen, sondern zugleich auch seine Projektionsfläche ${ }^{90}$ : „Multitude, solitude: termes égaux et convertibles pour le poète actif et fécond. Qui ne sait pas peupler sa solitude, ne sait pas non plus être seul dans une foule affairée.« (Oc I, S. 291)

Doch auch ein durchgehendes oder gar einheitliches «darstellerisches Ich ${ }^{91}$ gibt es in den Petits poèmes en prose nicht mehr. Baudelaire spaltet die Einheit des wahrneh-

Wohnung, die als Ort des Traumes und der Illusion, aber auch des Ausagierens aggressiver Impulse fungiert.

86

87 Doris Kolesch: Das Schreiben des Subjekts. Zur Inszenierung ästhetischer Subjektivität bei Baudelaire, Barthes und Adomo, S. 69.

88 Ebd., S. 34.

89 Eckhardt Köhn: Straßenrausch. Flanerie und kleine Form. Versuch zur Literaturgeschichte des Flaneurs bis 1933, S. 69.

90 Im Salon de 1859 heißt es programmatisch: mje préfère les monstres de ma fantaisie à la trivialité positiveu (Oc II, S. 620).

91 Eckhardt Köhn: Straßenrausch. Flanerie und kleine Form. Versuch zur Literaturgeschichte 
menden Individuums auf und erreicht so, was er in seinem 1851 veröffentlichten Essay $D u$ vin et du baschisch als Wirkung dieser beiden Rauschmittel beschrieben hat: eine multiplication de l'individualité (Oc II, S. 377) ${ }^{\mathbf{2}}$. Im Prosagedicht Les Foules hebt er denn auch die Fähigkeit des Dichters hervor, wêtre lui-même et autruik: sil entre, quand il veut, dans le personnage de chacun« (Oc I, S. 291). Dementsprechend erweisen sich die Texte der Petits poèmes en prose als Rollenprosa. Tendiert das Versgedicht spätestens seit dem Ende des 18. Jahrhunderts dazu, die Vielfalt sprachlicher Register auf einen Ton persönlichen Bekenntnisses zu beschränken, der obendrein gemäß dem Paradigma der Erlebnislyrik nur zu leicht mit der Ansicht des Autors verwechselt werden kann, so gestattet die Prosa nicht nur den Entwurf multipler, von Text zu Text wechselnder Ich-Identitäten, sondern bietet auch die Möglichkeit, neben der intimen Ich-Erzählung die distanzierte Er-Erzählung bzw. die Form des direkten Dialogs zu verwenden. Auf diese Weise entsteht ein raffiniertes Spiel mit verschiedenen Perspektiven und Rollen, das Baudelaire souverän nutzt, um Effekte der Ironie, Relativierung und Selbstzurücknahme zu erreichen. ${ }^{93}$

Zeigte sich schon in der Widmung an Arsène Houssaye meine Ironie, [...] die die Ebene des Sprachvollzugs selbst umfaßt ${ }^{94}$, so ergibt die eingehende Analyse der einzelnen Texte, daß letztlich die Gesamtheit der Petits poèmes en prose von einer ironischen Grundstruktur geprägt ist. ${ }^{95}$ Nachdem er das Verfahren des iSprechweisenwechsels ${ }^{96}$ bereits in den Fleurs du mal erprobt hat, die vals ein Experimentierfeld der verschiedenen Rollen, welche poetisches Sprechen ermöglicht, anzusehen «" sind, entwickelt Baudelaire es in den Petits poèmes en prose noch ungleich wirksamer

des Flaneurs bis 1933, S. 67. Schon Nies hat festgestellt: „Die Prosagedichte gruppieren sich [...] nicht mehr um das Zentrum eines unmittelbar engagierten Ich«; Fritz Nies: Poesie in prosaischer Welt. Untersuchungen zum Prosagedicht bei Aloysius Bertrand und Baudelaire, S. 276.

So der Untertitel seines Essays.

93 In $A$ une beure du matin beispielsweise führt er überaus ironisch den Rollenentwurf einer obsolet gewordenen Schriftstellerexistenz vor, indem er gezielt romantische Dichtungstopoi aufruft, die dann durch scharfe Kontraste lächerlich gemacht und in Frage gestellt werden.

94 Thorsten Greiner: Ideal und Ironie. Baudelaires Ästhetik der "modemité im Wandel vom Vers- zum Prosagedicht, S. 224.

95 Nies meint, daß »die Ironie [...] erst ermöglicht wird durch einen ganz bestimmten Habitus des poetischen Ich», den des "flâneur nämlich; Fritz Nies: Poesie in prosaischer Welt. Untersuchungen zum Prosagedicht bei Aloysius Bertrand und Baudelaire, S. 259.

96 Klaus Dirscherl: Zur Typologie der poetischen Sprechweisen bei Baudelaire. Formen des Besprechens und Beschreibens in den Fleurs du mal. München: Fink 1975 (= Romanica Monacensia 9), S. 179, Anm. 184.

97 Ebd., S. 41. Greiner hat im Anschluß daran noch genauer gezeigh, wie Baudelaire bereits in den Fleurs du mal-Gedichten versucht, die Ironie zum "Prinzip de eigenen Sprechens» zu machen; Thorsten Greiner: Ideal und Ironie. Baudelaires Ästhetik der wmodemité im Wandel vom Vers- zum Prosagedicht, S. 165. 
mzu einer dominanten Vertextungsstrategie ${ }^{98}$ auch der Prosa weiter. Durch die Nähe der Prosa zur Alltagssprache ${ }^{99}$ können in den Prosagedichten Stilregister zur Anwendung kommen, die im Rahmen der an metrische Regeln gebundenen Sondersprache der Lyrik per definitionem ausgeschlossen waren:

On nous présente le discours du monde journalistique ou théâtral; le discours de l'autorité, bien que dans la bouche de fées; le discours de la politique; le discours de la prière et de la religion; le discours du journal intime; le discours de la spéculation; le discours de vieux et de jeunes; le discours de la foire; les paroles de la courtisane; le discours du poète; et, pour, ne rien oublier, le langage des gestes du chien. ${ }^{100}$

Das Prosagedicht bei Baudelaire zeichnet sich durch seine Vielstimmigkeit aus, es ist, nach Stephens, whétéroglotte ${ }^{101}$. Aus diesem Grund auch kommt dem ersten Text der Petits poèmes en prose, dem Dialog L'Étranger, besondere Bedeutung zu: wLe monologisme habituel de la poésie est donc rompu dès l'abord et le dialogisme s'installe. ${ }^{102}$

Die Dialogizität des Prosagedichts bei Baudelaire resultiert aber nicht einfach aus dem per se vielstimmigen Charakter der Prosa, wie Stephens in Anlehnung an Bachtin annimmt, ${ }^{103}$ sondern sie ist das Ergebnis diverser künstlerischer Verfahrensweisen, von denen einige oben angedeutet wurden. Ebensowenig läßt das lyrische Ge-

98 Klaus Dirscherl: Zur Typologie der poetischen Sprechweisen bei Baudelaire. Formen des Besprechens und Beschreibens in den Fleurs du mal, S. 179, Anm. 184.

Mukařovský hat dies damit begründet, daß in der Prosa "das Quantum der mitteilenden, d.h. einer außerästhetischen Funktion größer istı als in den poetischen Gattungen; Jan Mukařovsky: Probleme des ästhetischen Werts. In: J. M.: Schriften zur Ästhetik, Kunsttheorie und Poetik. Hrsg. und übersetzt von Holger Siegel. Mit einer Einleitung von Miloš Sedmidubský und einem Nachwort von Thomas G. Winner. Tübingen: Narr 1986 (= Kodikas/ Code. Supplement 12), S. 9. Vgl. in diesem Zusammenhang auch Margot Kruse: "L'insolite et le quotidien«. Zur Gestaltung der Alltagswelt und zur Verwendung von Alltagssprache in Baudelaires Petits poèmes en prose, S. 275-296.

100 Sonya Stephens: L'Expérience urbaine et l'évolution d'un genre: le cas du poème en prose baudelairien. In: Le champ littéraire 1860-1900. Études offertes à Michael Pakenham, éd. par Keith Cameron et James Keams. Amsterdam/Atlanta (Georgia): Rodopi 1996 (= Faux titre 109), S. 43. So heißt es in einer entweder von Baudelaire selbst stammenden oder von ihm zumindest angeregten Ankündigung seiner Prosagedichte mit wünschenswerter Deutlichkeit: "Tout ce qui se trouve naturellement exclu de l'œuvre rythmée et rimée, ou plus difficile à y exprimer, tous les détails matériels, et, en un mot, toutes les minuties de la vie prosaique, trouvent leur place dans l'ouuvre en prose, où l'idéal et le trivial se fondent dans un amalgame inséparable.« (Oc I, S. 1297)

101 Sonya Stephens: L'Expérience urbaine et l'évolution d'un genre: le cas du poème en prose baudelairien, S. 43.

102 Ebd.

103 "Le poème en prose, discours à la frontiére de deux genres reconnaissables, est le dialogisme même«; ebd., S. 45. Stephens greift mit ihrer Argumentation auf Thesen zurück, die zuvor schon Monroe in seiner Studie A Ponerty of Objects. The Prase Poem and the Politics of Genre vertreten hatte, und enthistorisiert wie dieser die Ausdrucksmodi Lyrik und Prosa. 
dicht sich pauschal als monologische Form begreifen; durchaus aber trifft diese Einschätzung auf den historischen Zustand der französischen Verskunst Mitte des 19. Jahrhunderts zu. Als Reaktionen auf dieses zeitgenössische Defizit sind sowohl Baudelaires Versuch einer Erweiterung der Register lyrischen Sprechens in den Fleurs $d u$ mal als auch sein Experiment mit der Dekonstruktion poetischer Ausdrucksmodi in den Petits poèmes en prose ${ }^{104}$ zu verstehen. Befreit von den rhythmischen, strophischen und lexikalischen Konventionen der Poesie kann er erstmals daran gehen, der dissonantischen Vielstimmigkeit der Wirklichkeit in der Prosa zum Ausdruck zu verhelfen. Versteht man dergestalt die Prosa als entstellte Version der Versform, dann erscheinen die Petits poèmes en prose tatsächlich als »défigurations du langage poétique ${ }^{105}$.

Das gesamte Projekt der Prosagedichte läßt sich als Versuch deuten, die raspiration humaine vers une beauté supérieure« sowohl inhaltlich als formal mit ihrem Gegensatz, der "perversité primordiale de l'hommew (Oc II, S. 323), zu verkreuzen. Für diese permanente Desillusionierung, die dazu führt, daß sämtliche Ideale an der Realität zuschanden werden, erscheint die zwitterartige Gestalt des Prosagedichts als die geeignete Ausdrucksform, ruft sie doch immer wieder den hohen Anspruch der poetischen Sprache auf, um ihn umgehend mit der Drastik bzw. der Nüchternheit der Prosa zu konterkarieren. ${ }^{106}$ Wenn man also - wie der von Baudelaire als "peintre de la vie moderne" ausgerufene Constantin Guys - daran geht, wde chercher [...] la beauté dans la modernité« (Oc II, S. 718), oder versucht, das Ideal unter den Bedingungen der Moderne, die Poesie in der Prosa zu finden, dann lassen sich diese nur in entstellter Form entdecken. ${ }^{107}$ Hat Baudelaire in Les Fleurs du mal inhaltlich sle beau dans l'horrible ( (Oc II, S. 722) dargestellt, so spürt er in den Petits poèmes en prose auch formal dem Erscheinungsmodus der Poesie in ihrem Widerpart, der Prosa, nach.

${ }^{104} \mathrm{Vgl}$. hierzu auch Anne Jamison: Any where out of this verse: Baudelaire's prose poetics and the aesthetics of transgression. In: Nineteenth-Century French Studies 29 (2000/01), S. 192-203. So der Titel von Johnsons Studie über Baudelaires Prosagedichte.

106 Belegt wird dies durch einen am 7. Februar 1864 im Figaro erschienenen und mit dem Namen 》Gustave Bourdin« unterzeichneten Artikel über die Petits poèmes en prose, der mit größter Wahrscheinlichkeit entweder durch Baudelaire angeregt oder sogar von ihm selbst verfaßt worden ist. (Diese These hat erstmals Kopp vertreten; Charles Baudelaire: Petits poëmes en prose. Édition critique par Robert Kopp, S. LXIV. Die Herausgeber der CEurres completes schließen sich ihr weitgehend an; vgl. Oc I, S. 1297f.) Dort wird die Prosagestalt des in Vorbereitung befindlichen Werks folgendemaßen begründet: "Tout ce qui se trouve naturellement exclu de l'œuvre rythmée et rimée, ou plus difficile à y exprimer, tous les détails matériels, et, en un mot, toutes les minuties de la vie prosaïque, trouvent leur place dans l'œuvre en prose, où l'idéal et le trivial se fondent dans un amalgame inséparable.« (Oc I, S. 1297)

107 Wie das Prosagedicht Enimer-yous zeigt, bietet der Rausch die einzige Möglichkeit, in der verkommenen Realität der Ideale noch direkt ansichtig zu werden. 
Um der - entstellten - Schönheit zum Ausdruck verhelfen zu können, muß dazu die Kunst die ganze Häßlichkeit der Welt in sich aufnehmen. Baudelaire verfolgt also das paradoxe Unternehmen, die Poesie durch die Prosa zu vernichten, um sie eben dadurch zu retten. Indem sie im Prosagedicht ausgestrichen wird, bleibt sie als das Negierte doch sichtbar. ${ }^{108}$

Nicht zufällig finden sich denn auch in den Petits poèmes en prose zahlreiche Versatzstücke lyrischer Diktion: Sowohl Parallelismen - stout ce que je vois! tout ce que je sens! tout ce que j'entends (Oc I, S. 300), "vit la vie, rêve la vie, souffre la vie« (Oc I, S. 339) - und Interjektionen wie vahı und wô als auch erhabene sprachliche Diktion - »'azur tropicale“ (Oc I, S. 301) - und gewählte Metaphern wie »la coupole du ciel« (Oc I, S. 297) verweisen auf poetische Verfahrensweisen. Dies geht bis zum offenen Hinweis auf Gattungen der Lyrik; so nennt Baudelaire in dem Prosagedicht LHorloge eine Lobpreisung der Geliebten sun madrigal vraiment méritoire (Oc I, S. 300). Bleiben diese zitatartigen Anspielungen in ihrem Verweischarakter zumeist ambivalent, so begegnen daneben auch invertierte Bezugnahmen auf Konventionen der Versdichtung, denen ganz offenkundig die Funktion einer Negation zukommt. Ein charakteristisches Beispiel hierfür ist der Musenanruf, der sich in Les Bons Chiens findet. Hier verwirft das Dichter-Ich programmatisch die Muse der akademischen Dichtung und zieht dieser ausdrücklich die Muse des Alltags vor: »Arrière la muse académique! Je n'ai que faire de cette vieille bégueule. J'invoque la muse familière, la citadine, la vivante« (Oc I, S. 360) ${ }^{109}$ Bekanntlich ist der Musenanruf traditionell topischer Bestandteil poetischen Sprechens, durch den sich der Dichter die Fähigkeit erbittet, das Schöne und Erhabene zu preisen. Bei Baudelaire freilich wird in doppelter Inversion nicht nur der gewöhnliche, ja häßliche Gegenstand - nämlich »les pauvres chiens, les chiens crottés « (Oc I, S. 360) ${ }^{110}$ - gefeiert, besungen wird er auch nicht mit den Mitteln gebundener Sprache, sondern in einfacher Prosa. ${ }^{111}$ Folge-

108 Ausführlich entwickelt wurde der dialektische Zusammenhang der Durchstreichung - im Rückgriff auf Martin Heidegger - von Jacques Derrida; vgl. stellvertretend für andere Schriften von thm vor allem: Grammatologie [1967]. Aus dem Französischen von HansJörg Rheinberger und Hanns Zischler. Frankfurt a.M.: Suhrkamp 1983 (= suhrkamp taschenbuch wissenschaft 417), S. 42ff., 77ff., 99, 109 und 113.

109

Schon in den Fleurs du mal hatte Baudelaire zwei Gedichte an La Muse makde und an La Muse ténale gerichtet.

${ }^{110}$ Während in den Fleurs du mal noch die Katze als "poetisches" Tier eine wichtige Rolle spielt, bezieht sich Baudelaire in den Petits poèmes en prose bewußt auf den Hund als deren "prosaisches Gegenstücki; Thorsten Greiner: Ideal und Ironie. Baudelaires Ästhetik der modernitér im Wandel vom Vers- zum Prosagedicht, S. 273.

111 Metzidakis geht sogar soweit, von einer manti-ode formu (S. 43) des Textes zu sprechen: "Traces of the strict triadic form (strophe, metrically identic antistrophe, and epode) are also present, but only as violations of the ode's rules«; Stamos Metzidakis: Repetition and Semiotics: Interpreting Prose Poems. Bimingham (Alabama): Summa Publications 1986, S. 44. Als Beispiel dafür führt er er die drei Absätze mOù vont les chiens? [...] courent à 
richtig wird auch keine poetische Instanz, sondern der Romancier Lawrence Sterne um sun chant digne de toik (Oc I, S. 360) gebeten.

Baudelaires Dekonstruktion poetischer Konventionen erstreckt sich makrostrukturell bis in die Anordnung des Textes innerhalb der Sammlung und mikrostrukturell bis in die Wahl einzelner Wörter hinein. So bedient er sich ausgiebig einiger Ausdrucksmittel, die gewöhnlich dem hohen Stil zugerechnet werden: Wiederholungen, Anaphern und Parallelismen. Eine Textstelle wie die folgende etwa:

Je chante le chien crotté, le chien pauvre, le chien sans domicile, le chien flàneur, le chien saltimbanque, le chien dont l'instinct, comme celui du pauvre, du bohémien et de l'histrion, est merveilleusement aiguillonné par la necessité, cette si bonne mère, cette vraie patronne des intelligences! (Oc I, S. 361)

erinnert in gleichem $\mathrm{Maß}$ an die Psalmendichtung aus der Bibel wie an die französischen Versepen des 18. Jahrhunderts. Und ein durch Kursivierung hervorgehobener Binnenreim wie »bonbeur des hommes [...] l'bonneur des chiens» (Oc I, S. 362) wiederum verweist stellvertretend auf das für die französische Lyrik konstitutive Gebot der "richesse de la rime ${ }^{112}$

Zugleich placiert Baudelaire den Text innerhalb seiner Petits poèmes en prose auf höchst signifikante Weise: Anstatt den Musenanruf, wie es der Konvention entspricht, an den Anfang der Sammlung zu stellen, tut er genau das Gegenteil. Evans spricht zu Recht von der spseudo-conclusion of Les Bons Chiens with its paradoxical [...] device of putting the dedication, or invocation of the muse, at the endk ${ }^{113}$. Und während früher der Dichter als Gegengabe für wun precieux sonnet" oder wun curieux poème satirique von seinem adligen Mäzen noch mit Kostbarkeiten wie mune dague enrichie de pierreries« oder »un manteau de cour " geehrt wurde, erhält er für seinen Prosa-»Gesang « nurmehr von einem Gleichgesinnten einen abgenutzten Ge-

leurs plaisirs.« (Oc I, S. 361) an. "Though negativized in this particular text, the encomiastic tradition provides Baudelaire with an effective framework that he then employs in a personal or idiolectic way." Stamos Metzidakis: Repetition and Semiotics: Interpreting Prose Poems, S. 45. Doch der Musenanruf begegnet auch im antiken Epos, so daß der Rekurs auf die Ode zum Verständnis des Textes nicht unbedingt beiträgt.

112

Siehe hierzu den Abschnitt »Reimfülle» bei Hans Georg Coenen: Französische Verslehre. Ein Lehr- und Arbeitsbuch. Darmstadt: Wissenschaftliche Buchgesellschaft 1998, S. 88-90. Solche, zumeist im Dienst der Ironisierung stehenden Verfahrensweisen gestatten es freilich nicht, Baudelaires Prosagedichte der Spielart der poetischen Prosa< zuzuschlagen, wie dies noch Ortlieb tut; vgl. Comelia Ortlieb: Poetische Prosa. Beiträge zur modemen Poetik von Charles Baudelaire bis Georg Trakl, S. 23-75.

113

Margery A. Evans: Baudelaire and intertextuality. Poetry at the crossroads. Cambridge: Cambridge University Press 1993 (= Cambridge Studies in French 38), S. 156. Schon de George hat in der Positionsbestimmung dieses Textes eine Intention Baudelaires vermutet: "It seems that he deliberately placed this poem at the end for a specific reason, that it fulfilled a certain desire of the author.« Fernande M. de George: The Structure of Baudelaire's Petits poimes en prose, S. 145. 
brauchsgegenstand, wun beau gilet, d'une couleur, à la fois riche et fanée» (OC I, S. 362) - eine Parallele, die den Unterschied markant hervorhebt. ${ }^{114}$

Besonders charakteristisch für Baudelaires Umwertung traditioneller ästhetischer Normen ist also, daß die neuen Leitbegriffe dialektisch an das gebunden bleiben, was sie so vehement negieren. Wie das Böse und Häßliche seinen ästhetischen Reiz aus der Opposition zum verleugneten Guten und Schönen bezieht, ebenso erscheint das Vergängliche und Transitorische nur in bezug auf die Idee eines Ewigen strahlkräftig. Die Paradoxie, daß das Negierte in der Negation am Leben erhalten wird, ist ein konstitutives Moment von Baudelaires Ästhetik. ${ }^{115}$ Die Gattung poème en prose markiert bei ihm denn auch eine Gegensatzstruktur im fundamentalen Sinn. ${ }^{116}$ Die Lyrik verfügt auf Grund der Konventionen poetischen Sprechens nicht über die Fähigkeit, harte Kontraste zu gestalten, der Prosa wiederum mangelt es ihres mimetischen Charakters wegen an höchster sprachlicher Geschmeidigkeit. Beides zu verbinden, die "Integration gegensätzlicher Register $" ~{ }^{17}$ ist das Ziel der von Baudelaire angestrebten "prose poétique« (die allerdings nicht mit der unter gleichlautender Bezeichnung firmierenden, dem Typus Mischgattung zuzurechnenden lyrischen Prosa verwechselt werden darf). ${ }^{118}$ Die Gegensatzstruktur der Petits poèmes en prose ist verwandt jener von sspleen et idéal" in den Fleurs du mal, weitet das Kontrastmoment aber über den rein inhaltlichen Aspekt hinaus auf den Bereich der Form aus. Baudelaire konzipiert das Prosagedicht also im emphatischen Sinne als wcountergenre ${ }^{119}$,

114 Baudelaire greift hier - in scharfem Kontrast zur durchgehenden Kommerzialisierung des zeitgenössischen Literaturmarktes - auf den vormodemen Brauch zurück, wonach der poeta laureatus als Anerkennung für sein Werk eine symbolische Ehrengabe als Auszeichnung erhielt, die aber nicht als materielle Entschädigung für seine Mühe gedacht war.

115 Geradezu paradigmatische Gestaltung findet sie in dem Prosagedicht Laquelle est la uraie?

116 So zeigt sich Baudelaire in seinen Petits poèmes en prose als Musterbeispiel eines »destructeur initiateur«, wie Heine ihn charakterisiert hat, Heinrich Heine: Historisch-kritische Gesamtausgabe der Werke. Düsseldorfer Ausgabe. Hrsg. von Manfred Windfuhr. Bd. 15: Geständnisse, Memoiren und kleinere autobiographische Schriften. Bearbeitet von Gerd Heinemann. Hamburg. Hoffmann und Campe 1982, S. 121.

${ }^{117}$ Thorsten Greiner: Ideal und Ironie. Baudelaires Ästhetik der »modemité im Wandel vom Vers- zum Prosagedicht, S. 221.

118 In der Widmung an Arsène Houssaye wird die intendierte "prose poétique zweimal antithetisch charakterisiert: als "musicale, sans rythme et sans rime" und als "souplew und wheurtéer zugleich. Im Entwurf der Widmung wird das Ziel noch genauer umrissen durch die Formulierung, Baudelaire träume von einer "prose particulière et poétique« $(\mathrm{Oc} I$, S. 365). mPoétique» wird so zu einem Attribut der Prosa; gemeint ist damit die Fähigkeit, die "mouvements lyriques de l'âmen (Oc I, S. 275) zu übersetzen - "traduire (Oc I, S. 365) (so der Entwurf) oder, wie es dann in der gedruckten Widmung heißt, sich ihnen anzuschmiegen - "s'adapter (Oc I, S. 275). Verbunden werden soll die Innerlichkeit subjektiver Imagination, die etwa in den "ondulations de la rêverie zum Ausdruck kommt, und die geballte Faktizität modemer Lebenswirklichkeit, wie sie sich in den "villes énormes" und im "croisement de leurs innombrables rapports« zeigt.

119 Vgl. das Kapitel »Genre and Countergenre« in Claudio Guillén: Literature as System. Es- 
das nicht nur gegen eine bestimmte Gattung der Lyrik, sondern gegen den Ausdrucksmodus der Versdichtung insgesamt gerichtet ist. Dabei geht es ihm um eine Darstellungsweise, die sowohl inhaltlich wie formal das, was sie zum Ausdruck bringen möchte, nur erreichen kann, wenn sie ihren logischen Widerpart zum Medium der Aussage macht. Der sspleen« ermöglicht dem Ideal, sich in der modernen Welt zu artikulieren, drückt ihm aber zugleich das Stigma der Verschrobenheit auf und beraubt es damit seines metaphysischen Charakters. Ebenso vermag sich die Poesie nurmehr im Rahmen der Prosa Geltung zu verschaffen, wodurch sie mit ihrer Exklusivität auch die Basis ihrer Legitimität einbüßt.

Indem Baudelaire auf diese Weise ein generisches Paradoxon ${ }^{120}$ installiert, setzt er das Selbstverständnis moderner Kunst textuell ins Werk, die ja gleichfalls durch eine Widerspruchsstruktur geprägt ist, welche - funktionslogisch gesehen - ständig ihre eigenen Voraussetzungen untergräbt. Zugleich inszeniert er sich selbst als eine Art literarischer Demiurg, der seine Schöpferkraft dadurch demonstriert, daß er ein Gattungsmodell kreiert, das anders als alle bisherigen Textsorten funktioniert und sich - weil es auf einen feststehenden Satz generischer Merkmale verzichtet und auch nicht über ohne weiteres angebbare Vertextungsregeln verfügt - der Nachahmung im eigentlichen Sinne entzieht. Da eine komplex operierende Kommunikationsform wie das Prosagedicht letztlich nur auf dem Wege eigener Inventionskraft (neu) generiert werden kann, sind alle Versuche der bloßen Imitation notwendig zum Scheitern verurteilt. Baudelaire zwingt damit seine Nachfolger zur Originalität und fordert ihnen so jene Innovationsleistung ab, ohne die ein moderner Autor nicht bestehen kann.

says toward the Theory of Literary History, S. 135-158. Waming spricht in diesem Zusammenhang von einem »Konterdiskurs«; vgl. Rainer Waming: Baudelaire und der Wahnsinn der Dichter. Zum Prosagedicht Le Crépuscule du soir. In: Sprachlicher Alltag. Linguistik - Rhetorik - Literaturwissenschaft, S. 595.

120

Bauer hat Baudelaires Poetik des Prosagedichts mit Recht als "paradoxes und widersprüchliches Programm« bezeichnet; Roger Bauer: R.M. Rilke und das "Poème en prose Baudelaire'scher Prägung, S. 165. 
